\title{
Exploring the development of an innovation metric - from hypothesis to initial use
}

Peter Radziszewski

\author{
Correspondence: innov8.mining@ \\ gmail.com \\ Consultant, Vancouver, British \\ Columbia, Canada
}

\begin{abstract}
Purpose: The challenge to improving innovation in an organisation is limited by the metrics used to measure it. Dimensions related to where an organisation is on an innovation spectrum, how fast is that organisation innovating and what is holding it back are key elements that could be used to adequately measure innovation. The objective of this work is to explore the development of an innovation metric based on a pipe flow analogy that has the potential to provide insights into these key elements describing innovation.

Methodology: This work follows three steps: establishing a hypothesis, testing the hypothesis and applying the hypothesis. The proposed hypothesis suggests that an innovation metric, $R_{i r}$ can be developed based on a pipe flow analogy. This hypothesis is tested qualitatively and quantitatively. The quantitative assessment is accomplished by populating the innovation metric, $R_{i}$, with data mainly from the World Bank, comparing the results with established innovation and competitiveness metrics and examining if the metric confirms the trends suggested by the qualitative assessment. Using an illustrative case drawn from the quantitative assessment, the resulting innovation metric is used to indicate possible avenues for innovation performance improvement. Statistical analysis is limited to describing the goodness of fit of different trend line relationships.
\end{abstract}

Results: A qualitative assessment indicates that the innovation metric $\left(R_{i}\right)$ behaves as illustrated in the literature. The quantitative assessment confirms the qualitative assessment results. The illustrative case demonstrates how the innovation metric can be used to potentially orient innovation performance improvement. The paper closes with a discussion addressing issues and limitations of the metric.

Research limitations/implications: The validity of this innovation metric is limited by the variables defining it and the quality of the data input. Consequently, the variables used are limited to the analogous versions of fluid mechanics variables used to describe fluid flow in a pipe. The variables used require both hard and soft data which was obtained from the data sources cited as related to nations. On the other hand, the subsequent challenge is related to applying this model to ever smaller organisations especially with respect to gathering soft data related to trust and ease of communication.

(Continued on next page) 
(Continued from previous page)

Practical implications: Keeping in mind the limitations mentioned, the innovation metric, as it stands, can be used to describe an organisation's innovation performance, the speed of innovation and resistance to innovation with the data available from the sites indicated. As a result, the model also can be used to see how an organisation's innovation performance evolves over time as well as indicate possible avenues to improve innovation performance.

Originality/value: This is the first application of the fluid mechanics analogy to describe innovation performance. Its main value is related to contributing to the global conversation on innovation.

Keywords: Innovation, Organisations, Fluid mechanics, Reynolds number

\section{Introduction}

Apparently, the word "innovation" was not always seen as a compliment having evolved from an accusation akin to charges of heresy in the seventeenth century (Green, 2013). Even today, in some risk-averse industrial circles such as mining, innovation, as perceived, is likened to "be first to be second" or "...the second mouse gets the cheese". However, most if not all would agree that, independent of the industrial sector, the rate of change (or innovation) has increased substantially over the last number of decades and it is expected to continue to do so well into the future (Kotter, 2011).

This increase in the rate of change was illustrated by Eddie Obeng in his TED conference series presentation entitled "Smart failure for a fast-changing world" (Obeng, 2012) where he used a pipe flow fluid mechanics analogy to illustrate the rate of change that has been taking place in the world. Essentially, he illustrated that the rate of change has gone from what can be described as a "laminar flow" regime (see Fig. 1a) where change was quite slow and the interaction was few and far between to the current state that can be described as a "turbulent flow" regime (see Fig. 1b) where the rate of change has outpaced the rate of learning.

In using this analogy, Obeng also described that as the flow rate increased the change from laminar to turbulent was quite abrupt and sudden. In his words:

What's happened in this world of pipe is somebody has flipped it. They've changed the rules from laminar to turbulent. All the rules are gone. In that environment, instantly, all the possibilities which turbulence brings are available, and it's not the same as laminar. And if we didn't have the green ink, you'd never notice... ....and I

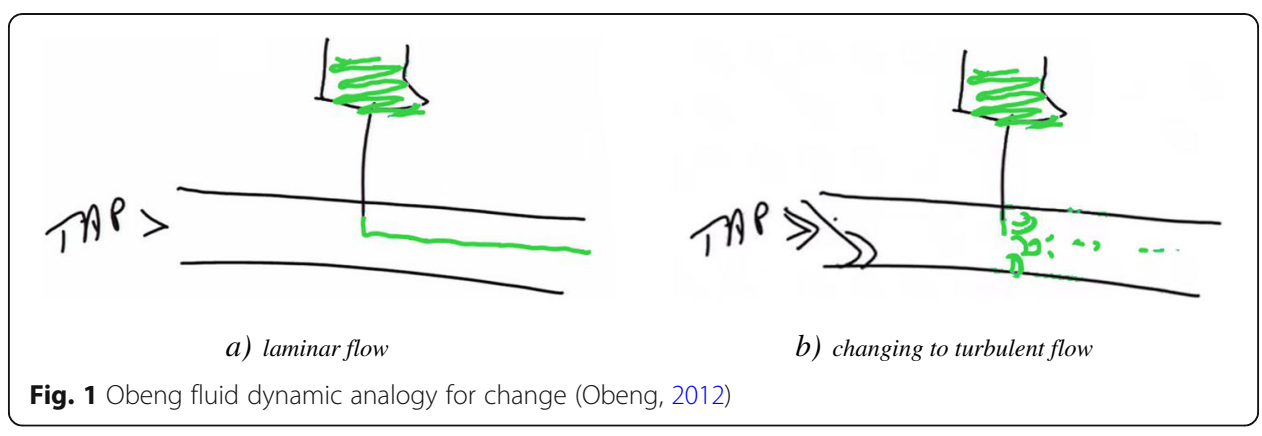


think this is our challenge, because somebody has actually increased... ...the speed, the scale and the density of interaction. (Obeng, 2012)

In this paper, an attempt is made to contribute to the innovation conversation by exploring the development of an innovation metric based on a pipe flow analogy. This will be accomplished by establishing a hypothesis, followed by testing the hypothesis and then by applying the hypothesis to a sample case. Finally, the paper will close with a discussion of some of the issues and limitations raised both by the metric development and the results as well as the challenges of applying the model across organisations of any size.

\section{Hypothesis}

If Obeng's analogy of pipe flow (Obeng, 2012) transition between laminar and turbulent conditions is indeed illustrative of the fast-paced innovation environment of the twenty-first century, then it is possible to suggest that an innovation metric could be defined using some fluid mechanics relationships that also captures this change.

In fluid mechanics, the Reynolds number is used to describe the transition between laminar and turbulent flow. It is commonly accepted that the transition between laminar and turbulent in pipes starts when the state of the flow has a Reynolds number of 2000 and becomes fully turbulent when the flow has a Reynolds number of 4000. If Obeng's analogy holds true and the state of innovation can be described by a pipe flow analogy, then a modified form of the Reynolds number should be able to capture the change in state of innovation in addition to capturing a transition from laminar type innovation and turbulent type innovation states.

Consequently, the hypothesis proposed here is that the following adapted form of the Reynolds number (see Appendix 1) can be used to illustrate the state of innovation $\left(R_{i}\right)$ of a given organisation as well as capture the transition between a "laminar" and a "turbulent" innovation state.

$$
R_{i}=\frac{4 \rho P L}{\pi \mu \Delta p D^{2}}
$$

In order to maintain the non-dimensional nature of the Reynolds number, the variables that compose this innovation metric are defined as follows:

$\rho$ is the density of ideas [number of ideas/population] or [number ideas/employee],

$L$ is the length of experience [number researchers]

$P$ is the power of research and development $(\mathrm{RnD})$ financial input $[\$ \mathrm{RnD} / \$ \mathrm{GDP}]$ or [\$ $\mathrm{RnD} / \$$ sales]

$\mu$ is viscosity or restrictions to communications, interactions and interdependence [unity]

$\Delta p$ is the loss to or cost of organisation [\$ total gov't expenditures/\$ GDP] or [\$ SG\&A/\$ sales]

$D$ is the distance between people involved [unity]

It should be noted that distance $(D)$ is not the distance between people. It is rather the inverse of trust.

Furthermore, $\pi$ and the constant 4 are holdovers from the pipe flow analogy and are considered here as scaling factors. 
Beyond the hypothesis that is captured in the adapted form of the Reynolds number (Eq. 1), there is no need to understand how the underlying Reynolds number was developed and used in fluid mechanics.

\section{Testing the hypothesis}

In order to prove or disprove the hypothesis, the innovation metric, $R_{i}$, is evaluated qualitatively and then quantitatively.

\section{Qualitative assessment results}

Qualitatively, it can be argued that the formulated innovation metric $R_{i}$, as defined by Eq. (1) and using the proposed variable definitions behaves as one would expect.

Essentially, it can be expected that an organisation's innovation performance as described by $R_{i}$ should increase if the density of ideas $(\rho)$ such as those described by patents and invention disclosures increase. This is supported by the works of Clark and Guy (1998), Galvez, Camargo, Rodriguez, and Morel (2013) and Vega Gonzalez (2005).

Innovation performance should also increase if the length of experience $(L)$ of the organisation's personnel increases. This is also supported by the works of Boh, Evaristo, and Ouderkirk (2014), Herstad, Sandven, and Ebersberger (2015) and Melero and Palomeras (2015).

Additionally, increased power of financial input into $\mathrm{RnD}(P)$ is expected to increase innovation performance $\left(R_{i}\right)$ which is supported by the work of Sheehan and Wyckoff (2003).

On the other hand, one can expect that as the $R_{i}$ metric shows, increased viscosity $(\mu)$ due to restrictions of communications and interactions will decrease innovation performance. This is supported by the works of Watson-Wyatt (2009).

Increased losses or the cost of organisation $(\Delta p)$ have a depressing effect on innovation performance as defined by $R_{i}$. This is supported by the reflections of Mitchell (2005) and a number of works cited there.

The distance $(D)$ or lack of trust between the people involved has a negative effect in the context of innovation and technological development. There are a number of works that support the effect of this distance or inverse of trust concept on business performance (Ibert \& Muller, 2015; Naef \& Schupp, 2009; Salamon, 2003).

This qualitative assessment indicates that the literature, as cited here, does not prove that the proposed hypothesis, which is based on a fluid mechanics innovation metric $R_{i}$, can describe the state of innovation of an organisation. However, this qualitative assessment also indicates that the literature does not disprove it either.

\section{Quantitative assessment results}

The objective of the quantitative assessment is the following:

(i) Populate the innovation metric $R_{i}$

(ii) Compare $R_{i}$ results with similar measures

(iii) Qualitative assessment confirmation 


\section{Populating $R_{i}$}

The challenge to populating the innovation metric, $R_{i}$, is the data required by Eq. (1). Although corporate annual reports do include numbers related to $\mathrm{SG \& A}$ and $\mathrm{RnD}$, it is doubtful that these reports include information on the number of employees involved in $\mathrm{RnD}$, the rate of patent filings and data outlining trust and restrictions to communications.

On the other hand, there are several data sources, such as the World Bank (http:// data.worldbank.org/), that have the required data to adequately populate the innovation metric, $R_{i}$. However, the use of these data sources requires the assumption that countries and nations can be reduced to mere organisations, or the contrary, it can be assumed that organisations can be elevated to the status of (borderless) countries and nations. Both of these assumptions can potentially be supported by the observations of Meyers (2016) that show that of the world's top 100 global economic entities, only 31 are countries while the remainder are corporations. Consequently, it will be assumed that from an economic entity point of view, countries and nations can be treated as organisations.

In addition to accepting data from the World Bank in this quantitative assessment, it is important to note that at the time of preparation of the data for this paper, it was noticed that a number of data points were missing for some years. In order to compensate for this missing data, an average of the values for the years 2010 to 2014 was applied. For any particular year in that range where there was a blank in the data, the average was determined over the "non-blank" years.

Consequently, the resulting quantitative assessment will be based on an innovation metric, $R_{i}$, populated with essentially the average values for the years 2010 to 2014 .

Despite the use of these averages, it was only possible to find complete sets of data for about a third of the countries in the World Bank database.

Density As described previously, density $(\rho)$ is a "per capita" metric that is defined by the number of patents, copyrights, trademarks, etc. produced by an organisation, or in this case a nation, divided by its population. One can argue that "population" should be its active population. However, in this development, it was assumed to be the actual population of a given country in a given year.

World Bank database contains it was possible to find the statistics for patent applications and trademarks made in a given year for a given country. It should be noted that a distinction is made between applications made by residents and non-residents. Only the numbers for patent and trademark applications for residents per country were considered in this analysis.

The average density of ideas for the years 2010-2014 is plotted against the relative size of the country (population over world population) in Fig. 2.

Length Length $(L)$ is defined as the number of researchers and research technicians in a given organisation. The number is determined by using the data for researchers and research technicians obtained from the World Bank database (numbers per million) and multiplying it with the population (in millions) in that organisation. The results are plotted in Fig. 3 against relative size. 


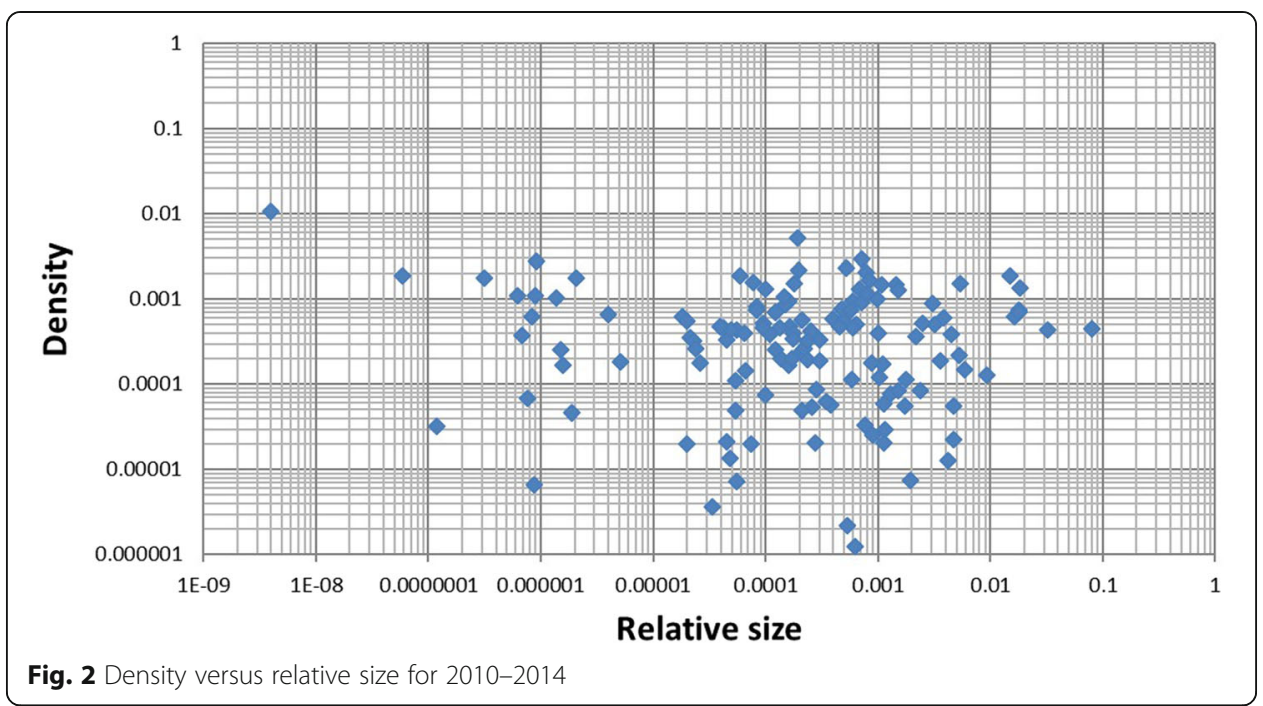

Power This power $(P)$ parameter is defined as the \%GDP used in $\mathrm{RnD}$ in a given country, and it is plotted against relative size in Fig. 4.

Viscosity As previously indicated, viscosity $(\mu)$ is essentially the contrary to ease of communication, interactions and interdependence. For organisations, this metric would normally be quantified with a survey. In the present case, a similar metric can be found in the World Bank database which describes the "ease of doing business" in a given country. A rating of " 1 " on this metric indicates "most businessfriendly regulations" which reflects low viscosity or restrictions related to communications, interaction and interdependence. Viscosity is plotted against relative size in Fig. 5.

Losses Losses metric $(\Delta p)$ for organisations such as countries is defined as the total governmental expenditures as expressed by \%GDP as illustrated in Fig. 6.

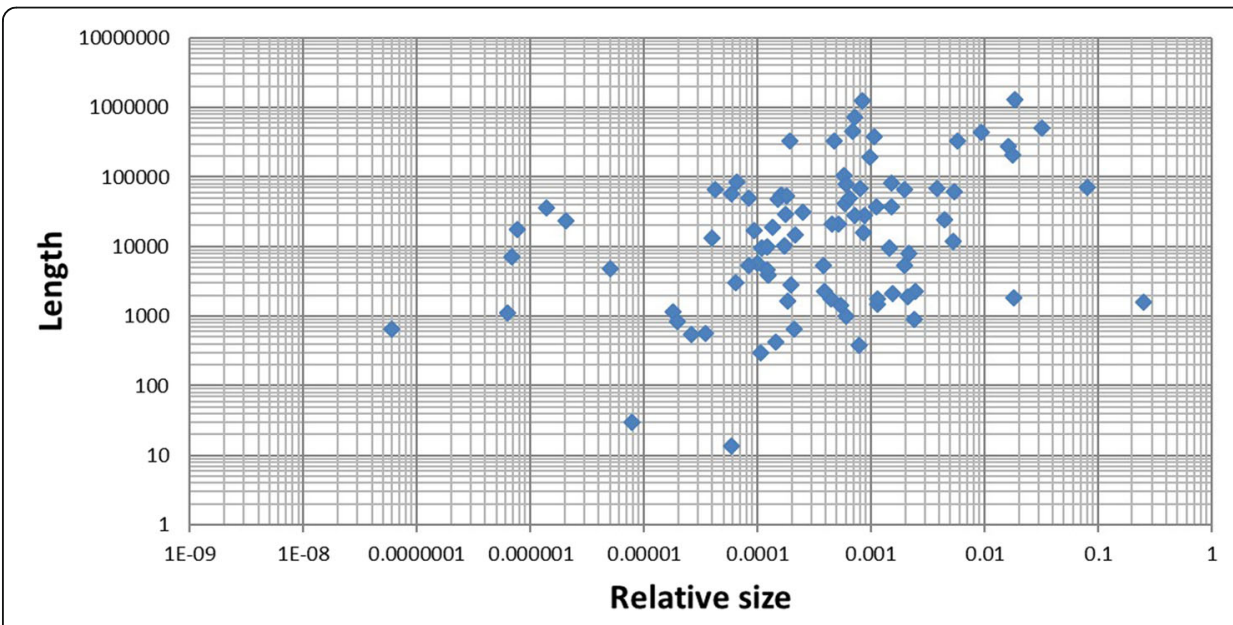

Fig. 3 Length versus relative size for 2010-2014 


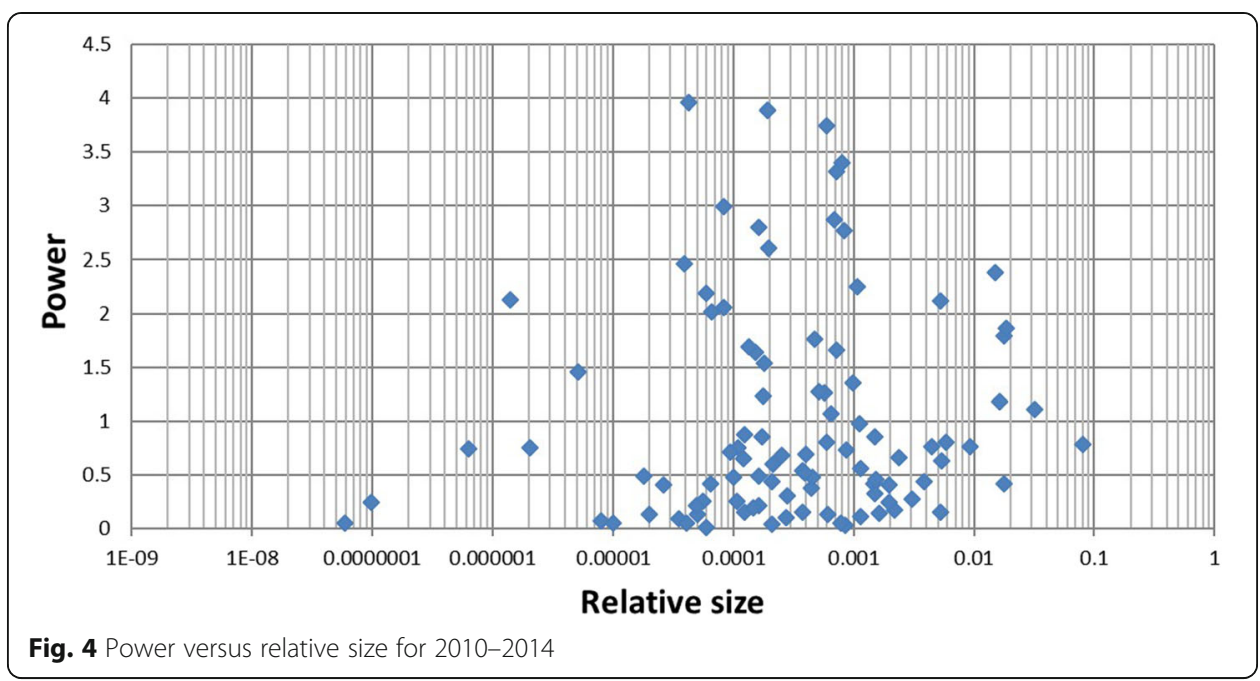

Distance Distance $(D)$ is a metric defining the degree of trust between people and organisations. Nominally, people and organisations with a high degree of trust or little distance between them easily exchange ideas and concepts that may lead to inventions, products and services. Through this logic, it can be expected that the contrary is also true.

Unfortunately, metrics describing trust at the national level could not be found. This dilemma can be overcome by taking note of the works of Morris and Klesner (2010) and that of Smith and Cruickshank (2017) indicating that increased levels of trust are associated with the absence of corruption. Both works suggest that there is an inverse relationship between trust and corruption. Consequently, a national corruption index could be a good proxy for the measurement of distance (inverse of trust).

Two metrics on corruption were found: one from the World Bank data set- "informal payments to public officials"-and the other from Transparency International"corruption perception index" (CPI, 2014). In this analysis, the CPI will be used as it

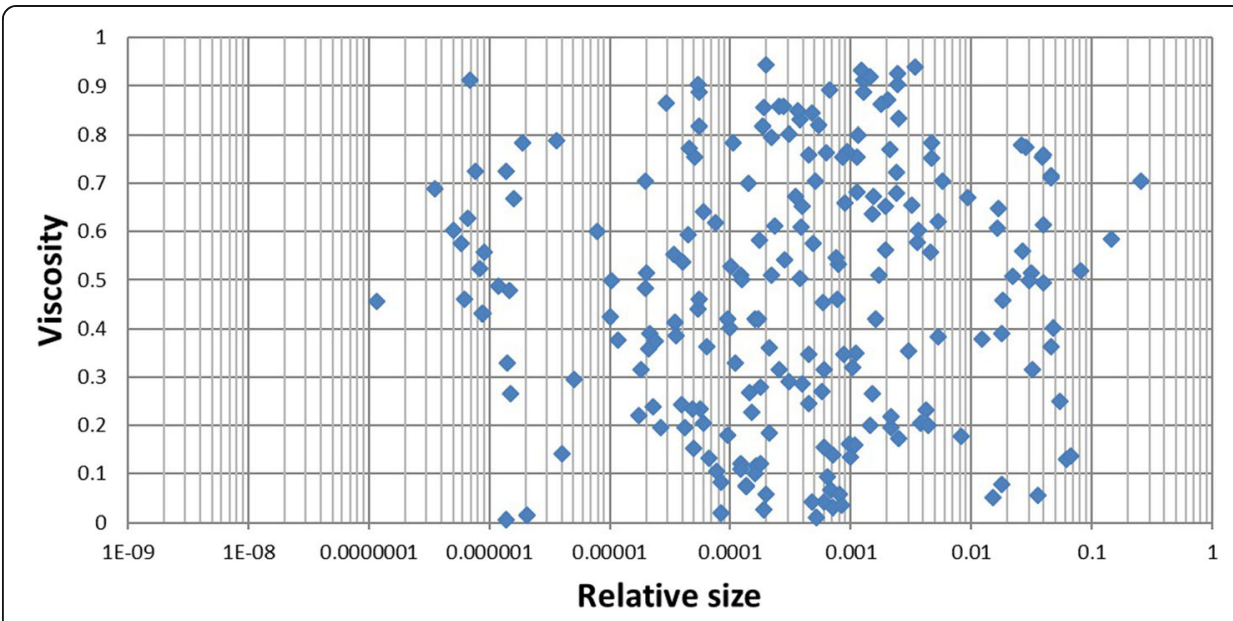

Fig. 5 Viscosity versus relative size for 2010-2014 


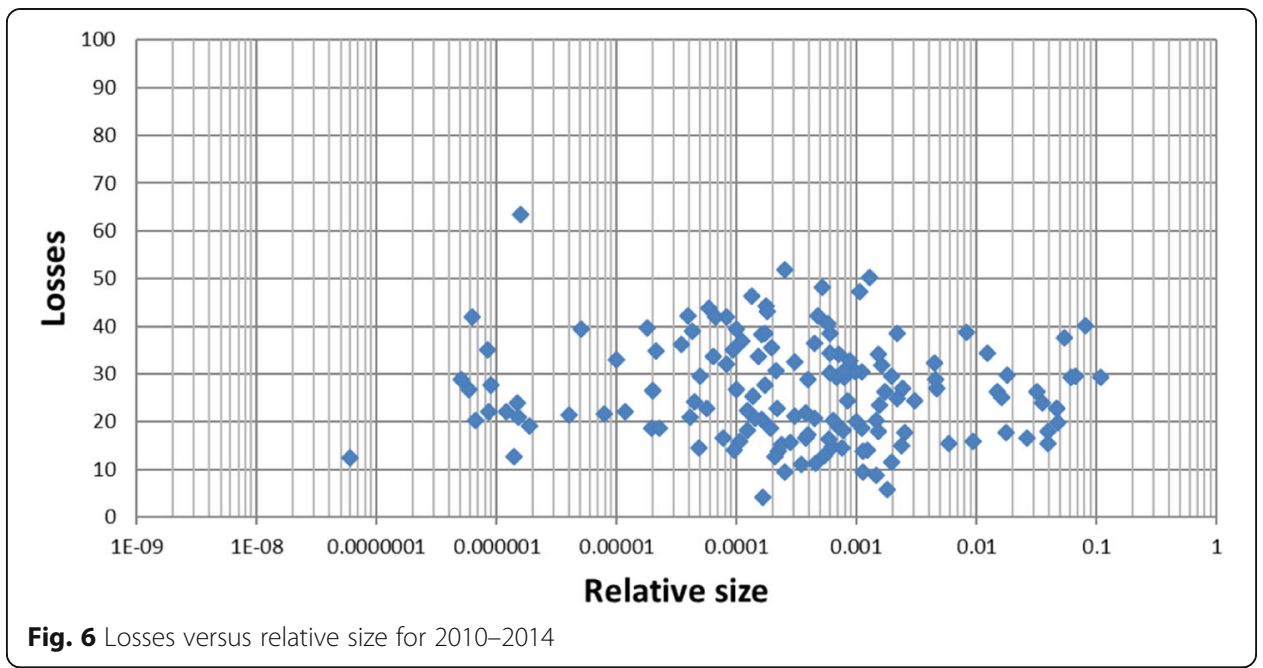

includes values for Western countries. It should be noted that the CPI index is fitted onto a 1 to 100 scale which is subtracted from 100 in order to reflect a growing distance with an increased level of perceived corruption scaled index. The result is plotted against relative size in Fig. 7.

Having found a data set that covers all of the variables used in the innovation metric definition (Eq. 1), the first observation that can be made is that the data presented in Figs. 2, 3, 4, 5, 6 and 7 has no apparent correlation with the relative size of the organisations (nations) plotted. After populating the innovation metric $\left(R_{i}\right)$ with this data, the results are plotted on the horizontal axis in Fig. 8. Relative size is plotted on the vertical axis.

A second observation demonstrates that the resulting $R_{i}$ figures obtained span a range that overlaps the definition of turbulent flow transition at $\operatorname{Re}=2000$. As a result, it can be suggested that countries with $R_{i}$ greater than 2000 have reached a state of innovation that reflects a "turbulent" flow of ideas and knowledge.

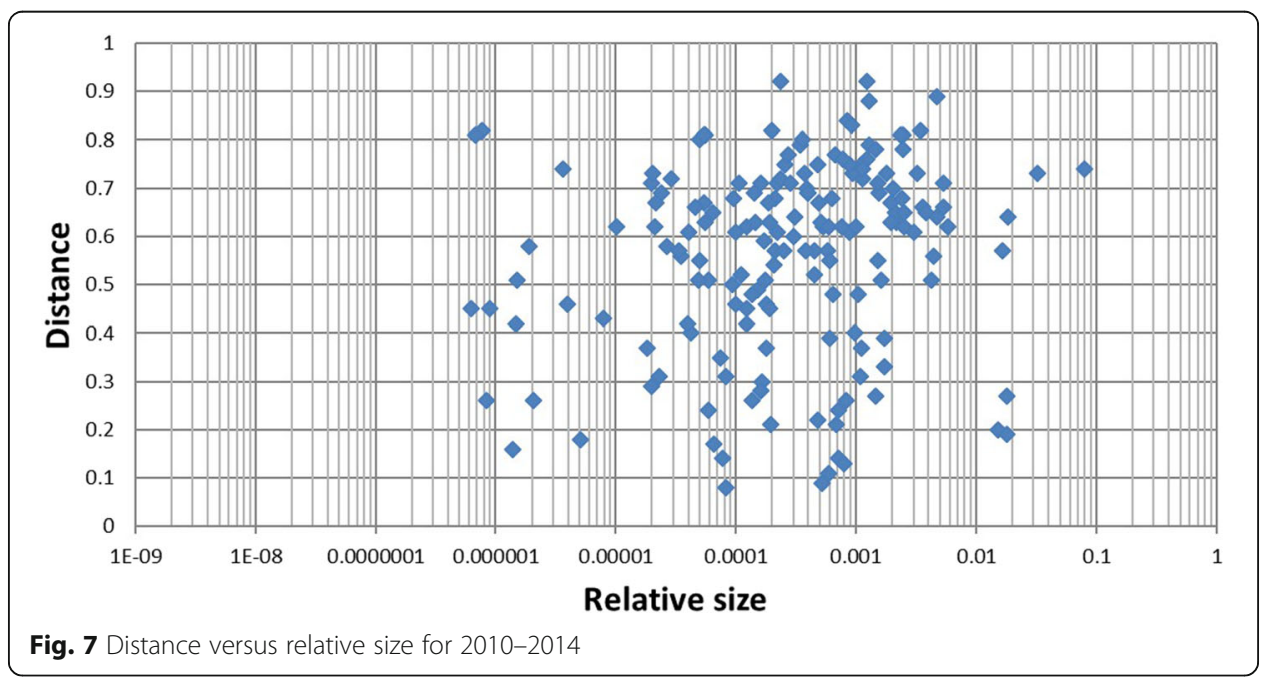




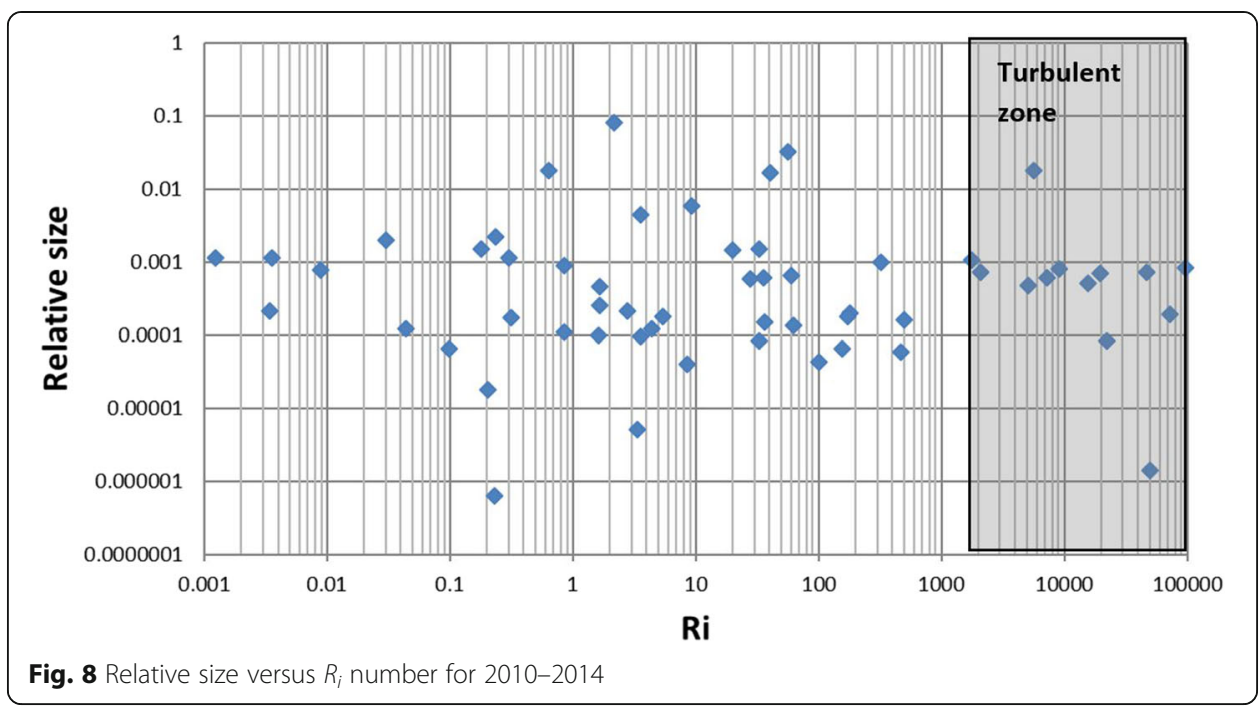

\section{Comparison with established metrics}

Despite demonstrating that the $R_{i}$ index can be successfully populated with data from the World Bank and produce a result that spans an innovation space defined by $R_{i}$, including values that can be characterised as "laminar" and "turbulent", the results presented in Fig. 8 do not prove that the $R_{i}$ index actually measures the state of innovation for an organisation such as a country or nation. In order to assess this, the results produced by the $R_{i}$ index need to be compared with established indices. If the comparisons produce reasonable correlations, then it can be concluded that the $R_{i}$ index does indeed provide a measure of the state of innovation.

Two comparisons are possible at this point, comparison against established innovation indices and against established competitiveness indices.

In the case of innovation indices, Fig. 9 shows that the $R_{i}$ index compares well with both the Bloomberg Innovation Index (BII, 2015) and the Global Innovation Index (GII, 2014). This suggests that the $R_{i}$ metric is a comparable metric to both established indices.

With respect to a comparison with established competitiveness indices, according to the review by Clark and Guy (1998), "the consensus of opinion, backed up by strong empirical evidence, is clearly that innovation has an important positive effect on competitiveness". A more recent review by Backman and Ellmarker (2017) confirms this conclusion by stating: "It can be concluded that innovation drives economic growth".

Both observations suggest that there should be a correlation between the innovation metric, $R_{i}$, and other competitiveness metrics found in the literature. At the national scale, three such metrics can be found: the Global Competitiveness Index (GCI, 2018), the IMD World Competitiveness Index (IMD, 2018) and a European Competitiveness ranking (Annoni \& Dijkstra, 2013). Plotting the national competitiveness scores against the innovation metric, $R_{i}$, determined for the years 2010-2014 produces the trends displayed in Fig. 10. 


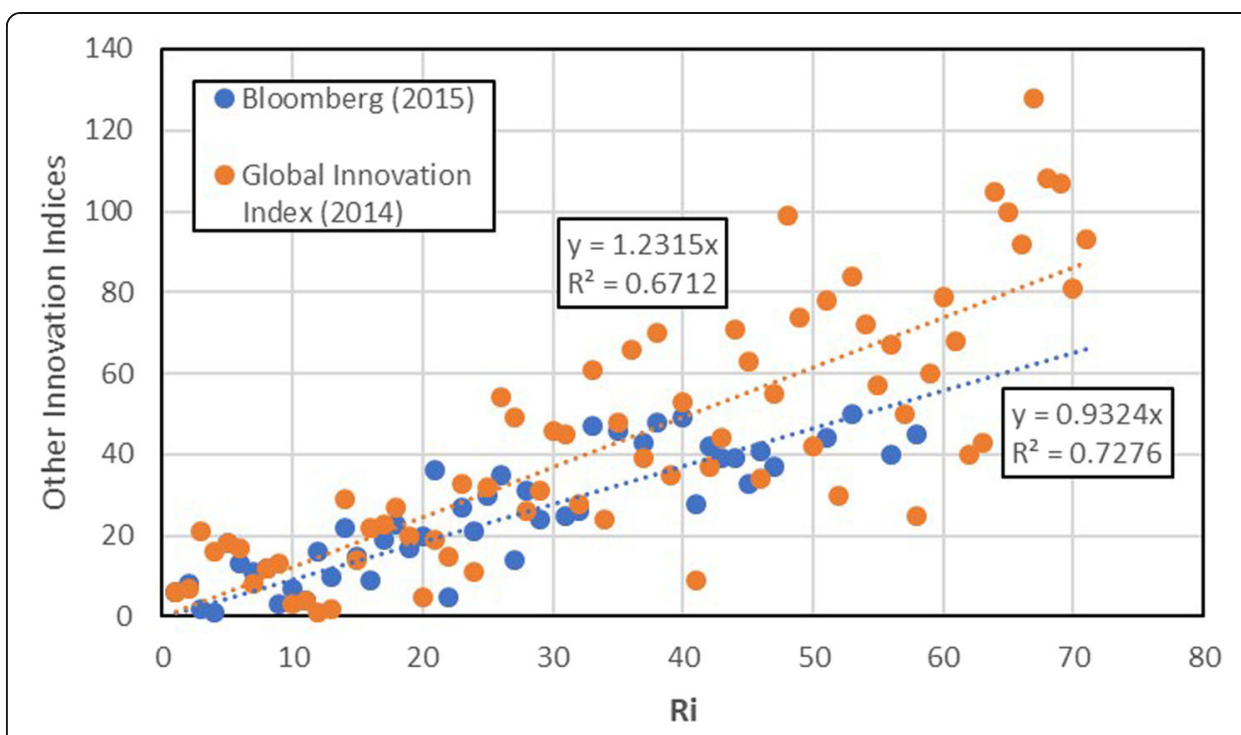

Fig. 9 Correlation between two innovation indices and the 2010-2014 $R_{i}$ metric

The correlation with $R_{i}$ is low for both the EU 2013 competitiveness ranking and the IMD 2015 ranking. Nevertheless, a reasonable trend is indicated. On the other hand, the correlation between the GCI rankings and the innovation metric is quite strong.

Further examining the comparison with the GCI, an effort was made to determine if the innovation metric, $R_{i}$, also correlated with GCI's distinction between factor-, efficiency- and innovation-driven economies. These results are plotted in Fig. 11.

Examining this comparison suggests that the $R_{i}$ laminar to turbulent innovation thresholds should probably be lower than 2000 (onset of turbulent flow) and 4000 (fully turbulent flow). Based on the comparison with the GCI metric, the thresholds could potentially be as low as $R_{i}=1$ for the onset of turbulent flow, and $R_{i}=$ 100 for fully developed turbulent flow. Above $R_{i}=100$, according to the GCI data

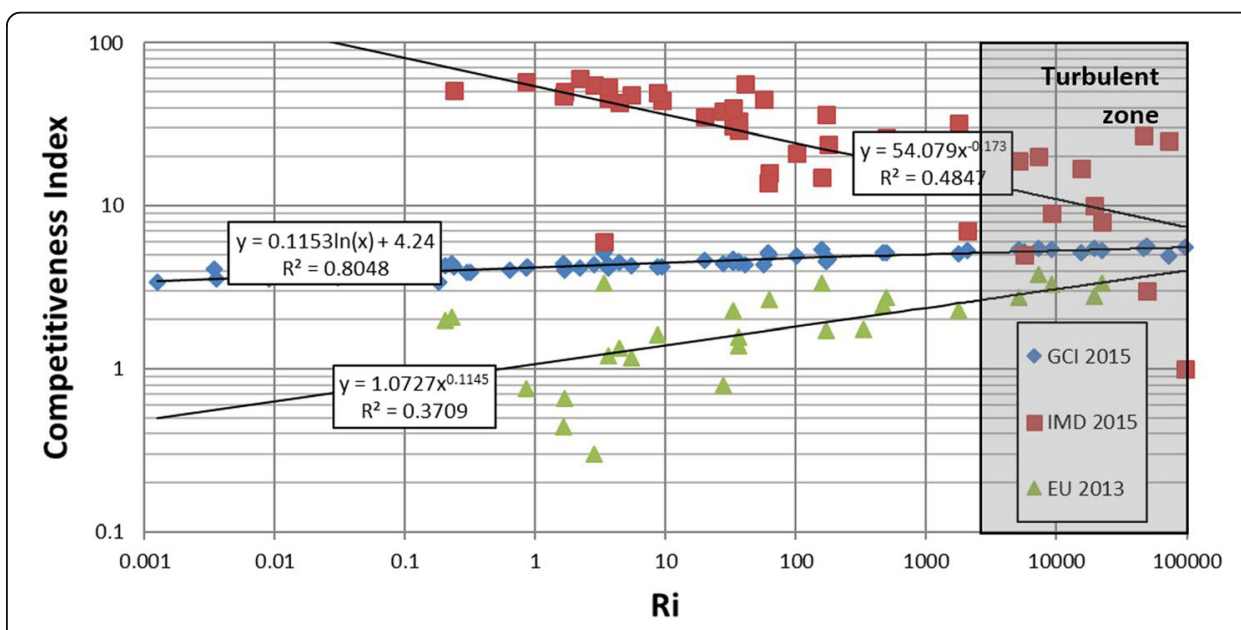

Fig. 10 Relationship between a few competitiveness indices and the innovation metric, $R_{j}$, for 2010-2014 


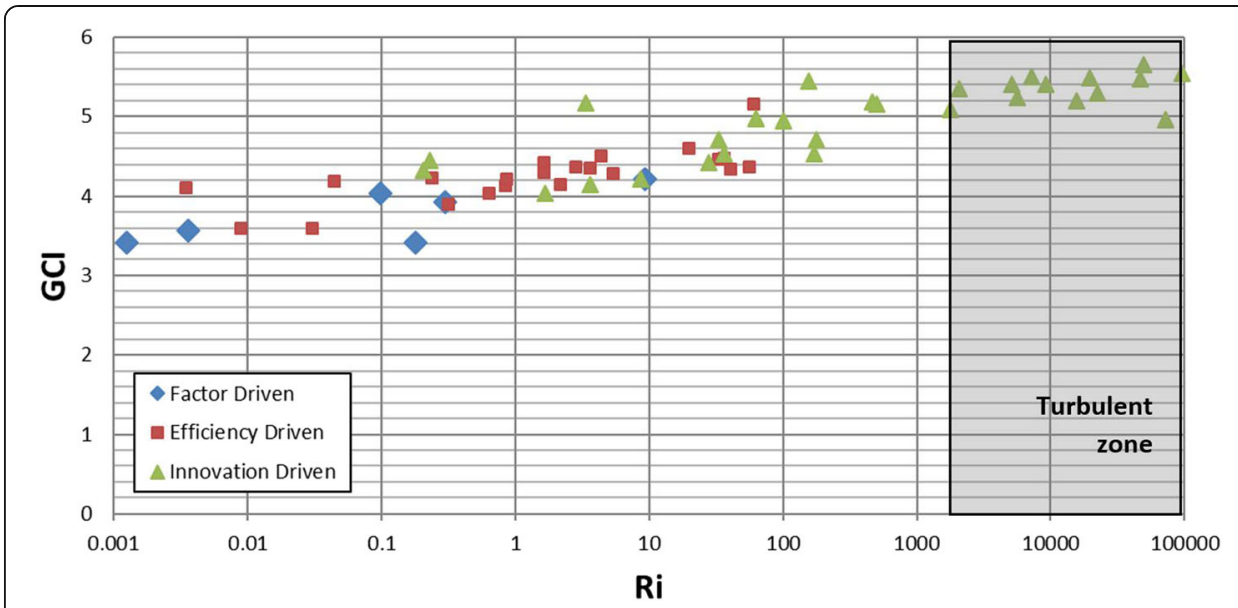

Fig. 11 Relationship between GCl's Factor, Efficiency and Innovation metrics and the innovation metric, $R_{i}$

set, only innovation-driven economies are found. The zone between $R_{i}=1$ and $R_{i}$ $=100$ can be considered a laminar to turbulent transition where only efficiencyand innovation-driven economies overlap. Below $R_{i}=1$, despite the presence of factor, efficiency- and innovation-driven economies, this zone would be considered a laminar only innovation flow zone. More research would be required to appropriately define the $R_{i}$ thresholds.

\section{Qualitative assessment confirmation}

The qualitative assessment will be confirmed through a sensitivity analysis, of which there are numerous methods of evaluation (Hamby, 1994). For this case, an initial "local" sensitivity analysis can be completed by examining the $R_{i}$ number definition as described by Eq. (1). When doing so, it is easy to see that the $R_{i}$ metric is proportional to density of ideas, financial power input to $\mathrm{RnD}$ and the length of experience as well as inversely proportional to viscosity, losses and the square of the distance.

However, by plotting $R_{i}$ against each individual component, another dimension of the metric's sensitivity can be explored. Sensitivity to changes in parameter values can be further examined by plotting "one factor at a time" $R_{i}$ against each of the model parameters and determining the "best fit" trend line for each parameter. This is illustrated in Fig. 12. It is interesting to note that most of the trend lines are of a power function format, confirming the general trends identified in the qualitative assessment. Specifically, the state of innovation increases with increasing density of ideas (Fig. 12a), length of experience (Fig. 12c) and the power of RnD financial input (Fig. 12b). On the other hand, the state of innovation decreases with increasing viscosity or restriction to communication (Fig. 12d) as well as increased distance (Fig. 12f) as illustrated by corruption. There is an outlier found in Fig. $12 \mathrm{e}$, where losses show the least correlation with the $R_{i}$ metric. With one exception, it appears that the innovation metric is quite responsive to the variables that compose it. 


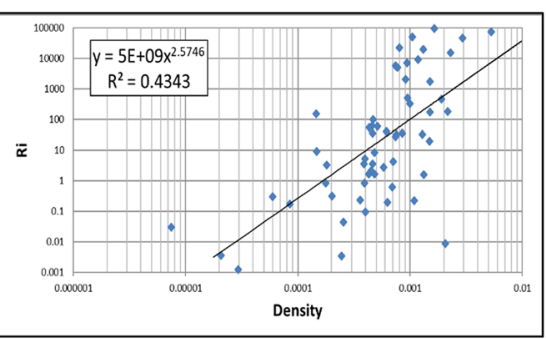

a) Density

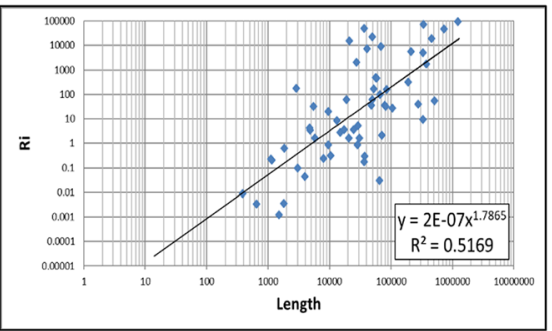

c) Length

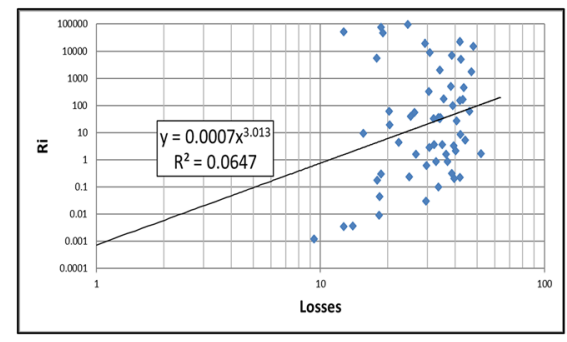

e) Losses

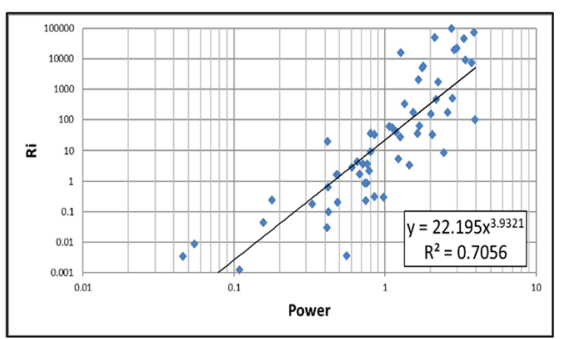

b) Power

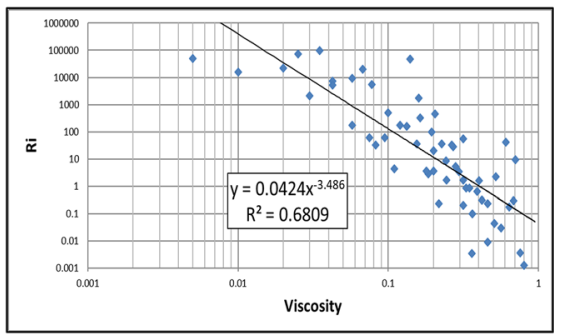

d) Viscosity

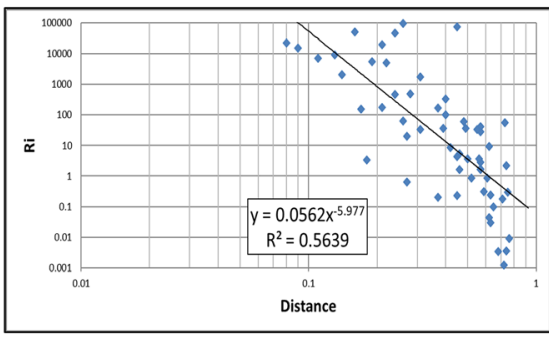

f) Distance

Fig. $12 R_{i}$ number as a function of different individual

Despite the good levels of both responsiveness and correlation found, the lack of sensitivity to changes in organisational Losses (Fig. 12e) is a bit worrisome. This is compounded when one considers the documented relationship between the cost of government and national economic development illustrated by the work of Mitchell (2005). On the other hand, one could suggest that there are almost three distinct regions in the data displayed in Fig. 12e. This distinction also becomes more apparent when grouping nations according to $R_{i}$ values as illustrated in Fig. 13. Essentially, with high $R_{i}$ nations (innovation driven, GCI, 2018), it seems that the higher the innovation performance, the lower the Losses or cost of government. The contrary seems to be true for low $R_{i}$ nations (factor driven, GCI, 2018). While for the nations found between these two limits (efficiency driven, GCI, 2018), there is no real correlation between the innovation metric and the cost of government (Losses).

Returning to the observation that the $R_{i}$ threshold limits might be lower, Fig. 13 tends to confirm that the transition from laminar to turbulent flow starts around $R_{i}=1$. However, fully turbulent flow would be closer to $R_{i}=1000$.

Based on these observations, one could suggest that the relationship between $R_{i}$ and the cost of government (Losses) could potentially be a parabolic function. This is 


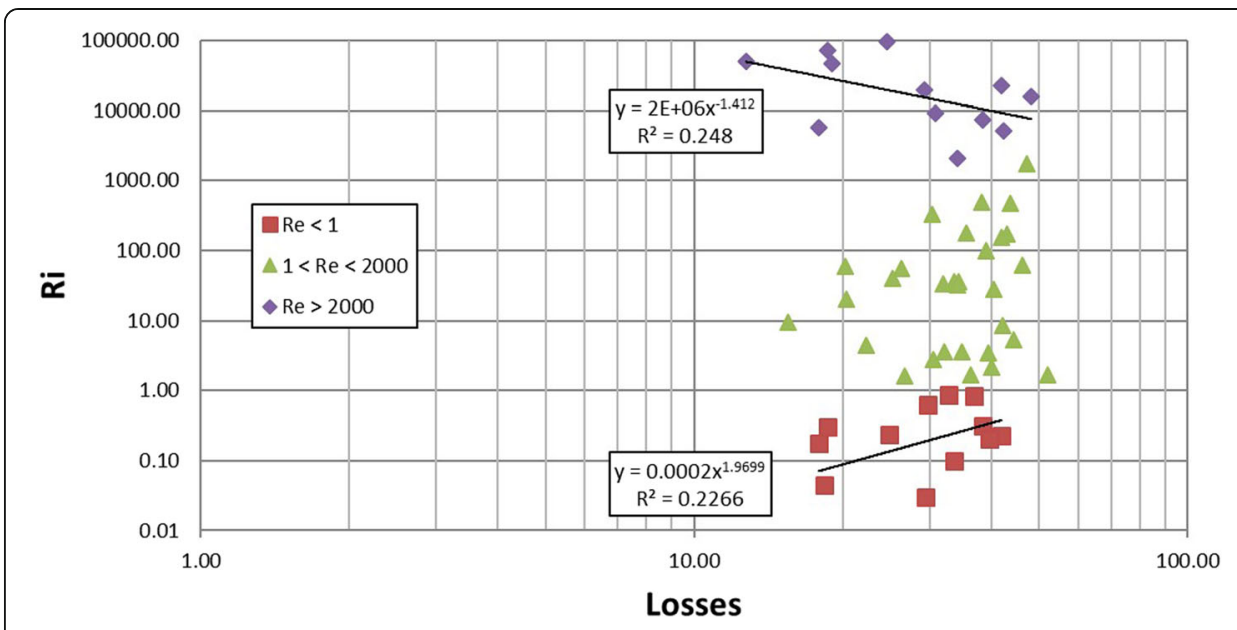

Fig. 13 Ri vs Losses in three regions

further investigated by plotting the Log exponents for both $R_{i}$ and losses with inversed axes as illustrated in Fig. 14.

Using the trend line in Fig. 14, it was possible to define the following parabolic function:

$$
0=-0.0168 \log \left(R_{i}\right)^{2}+0.0583 \log \left(R_{i}\right)+(1.4965-\log (\text { Losses }))
$$

The solution to this parabolic function is:

$$
\log \left(R_{i}\right)=1.7351 \pm \sqrt{0.001129+59.5238(1.4965-\log (\text { Losses }))}
$$

Figure 15 illustrates the results of Fig. 12e overlaid with the solution defined by Eq. (3).

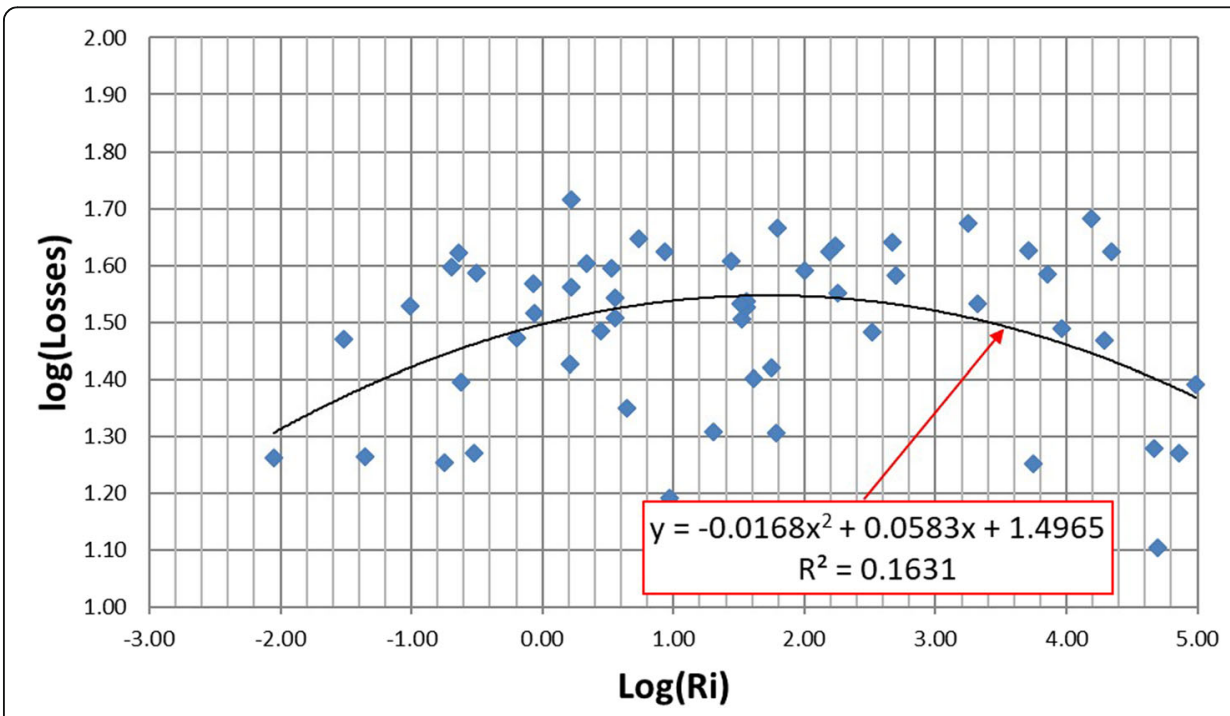

Fig. 14 Log Losses vs Log $R_{i}$ 


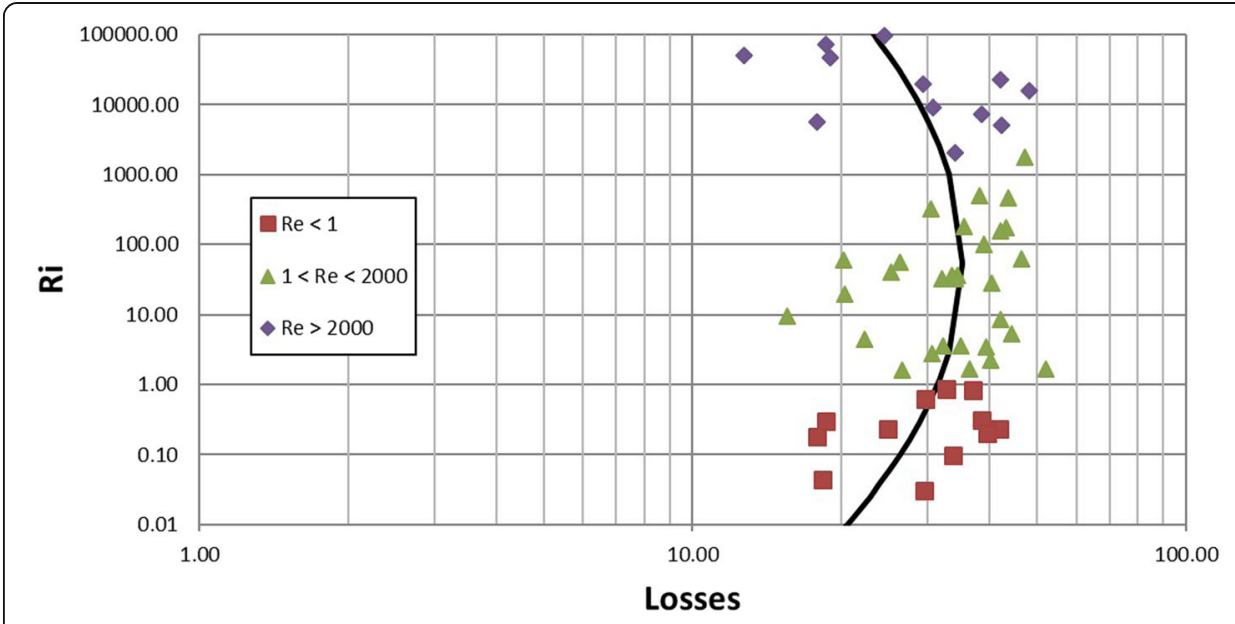

Fig. 15 Possible relationship between innovation performance $\left(R_{i}\right)$ and cost of government (Losses)

More investigation is required to confirm such a relationship between innovation performance and Losses.

\section{Applying the hypothesis}

After having tested the hypothesis and demonstrating that the resulting innovation metric, $R_{i}$, produced a ranking of organisations (countries in this case) comparable to those determined from established innovation and competitiveness indices, some effort is still required to illustrate how the metric could be used to track and improve an organisation's innovation performance.

Let's consider the innovation performance as measured by $R_{i}$, for the five organisations found in Fig. 16. Four of the five are the top organisations, as determined in the previous quantitative assessment (see Fig. 8), while the fifth organisation falls in 8 th position. It is interesting to note that over a similar period of time, organisation 1 has maintained approximately the same state of

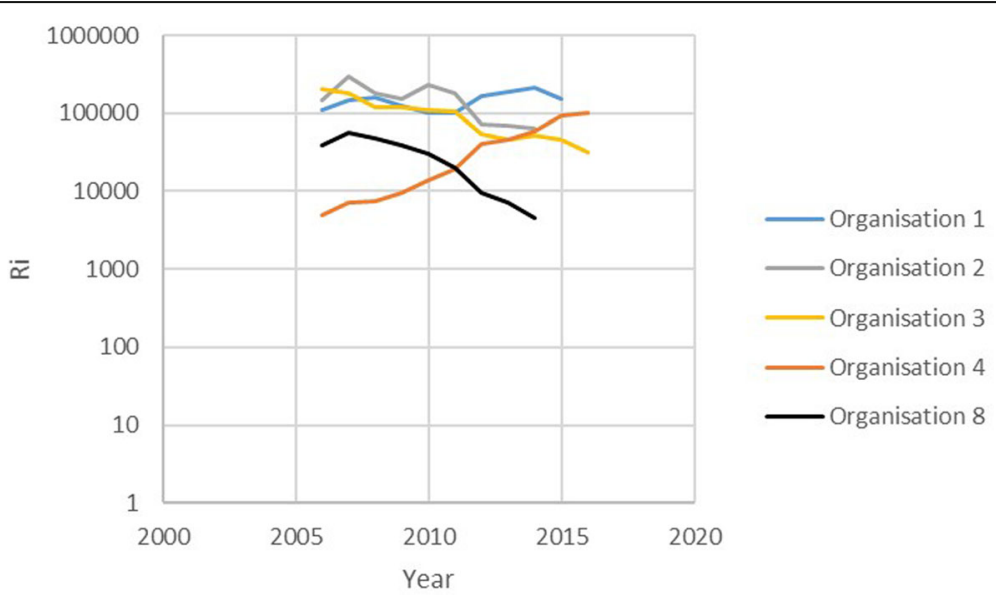

Fig. $16 R_{i}$ performance of the top innovation organisations and the 8th place organisation 


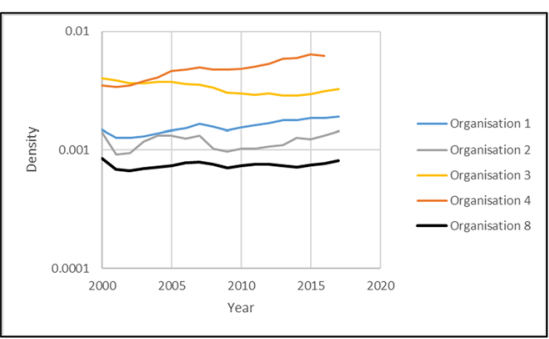

a) Density

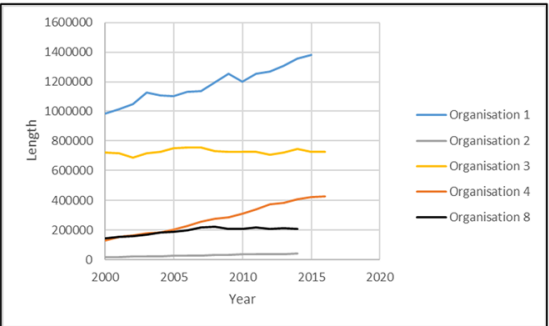

c) Length

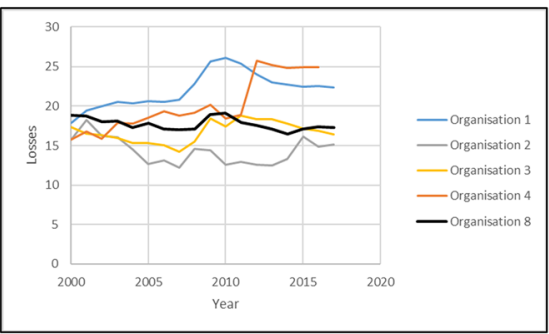

e) Losses

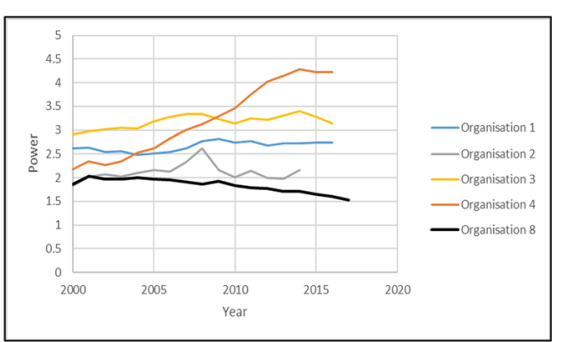

b) Power

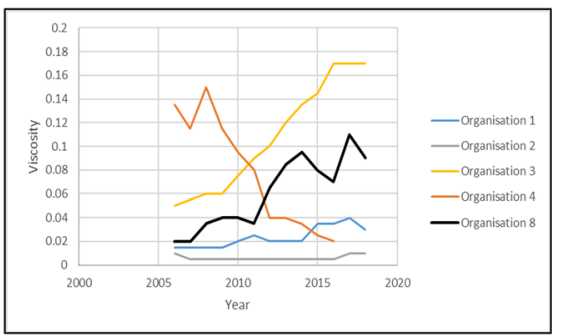

d) Viscosity

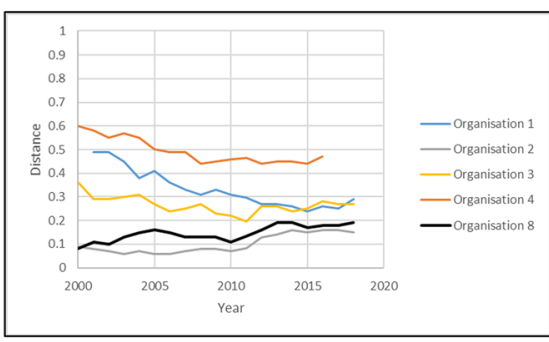

f) Distance

Fig. $17 R_{i}$ parameter values per selected organisation

innovation $\left(R_{i}\right)$ while organisations 2 and 3 have decreased their respective innovation performance somewhat. The greatest contrast is found between organisation 4, which has increased its performance significantly, and organisation 8, which demonstrated a significant decrease in innovation performance over this same period. This diverging dynamic can be explained by observing how individual parameters of these two organisations have evolved over time.

Starting with Density (Fig. 17a), organisation 4 generates many more patents and trademarks per capita as compared with organisation 8. Furthermore, organisation 4's Density has been steadily increasing, while country 8's Density was essentially stable. Length (Fig. 17c) defined by number of researchers and technicians has stayed stable in organisation 8, while it increased somewhat for organisation 4 . Losses (Fig. 17c) defined by government expenditures were equally stable for organisation 8 while it increased for organisation 4 .

However, the greatest differences between organisations 4 and 8 are related to Power (funds in RnD), Viscosity (restrictions to doing business) and Distance (corruption index). Organisation 4 experienced significant increases in Power while dropping significantly Viscosity and Distance. Organisation 8 took an opposite path decreasing Power while increasing Viscosity and Distance. 
Potentially, organisation 8 could learn from the experience of organisation 4 in order to turn around the downward slide in innovation performance.

\section{Discussion}

Through the previously discussed qualitative and quantitative assessment, the hypothesis that a pipe flow analogy can be used to illustrate the state of innovation $\left(R_{i}\right)$ for an organisation has been proven. However, a number of issues and limitations remain, namely the following:

(i) Impact of distance " $\mathrm{D}$ "

(ii) Causal vs correlational

(iii) Validity of the parameters used

(iv) Possible other fluid mechanical analogies

(v) Conceptual model of an organisation

(vi) From nations to corporations and companies

(vii)Relationship with the literature

These issues are addressed as follows.

\section{Impact of distance " $D$ "}

In the formulation of the innovation metric, $R_{i}$, which is based on the pipe flow analogy, the impact of distance $(D)$ on innovation performance is somewhat greater than the other parameters as $D$ is squared in Eq. (1). The qualitative assessment provided no indication that confirms such an importance. On the other hand, there is nothing in that assessment that disproves it either.

By examining the results of the quantitative assessment presented in Fig. 12, some insight can be obtained. All the trend line relationships between $R_{i}$ and the individual parameters are power functions with different exponents. This indicates that each parameter will have a greater or lesser impact on $R_{i}$. In the case of $R_{i}$ vs Distance (Fig. 12f), the absolute value of the exponent is 5.977, while the absolute values of remaining parameter exponents are less than 4 . This observation indicates that small variations in $D$ will have a greater impact on $R_{i}$ than the other parameters.

Taking this into account, it is possible to suggest that the distance $D$ does indeed have a greater impact on innovation performance than the other parameters. Furthermore, knowing that $D$ is the inverse of trust, this observation suggests that trust is an important component in an innovative environment. Further research is necessary to confirm this observation.

\section{Causal vs correlational}

Despite proving the hypothesis, there is no indication that the definition of the $R_{i}$ innovation metric is casual. It may very well be a happy convergence of data and model form. On the other hand, if the relationship (Eq. 1) is causal to the same degree as defined by established innovation and competitiveness indices that it was 
compared with, then one could suggest that there is merit in exploring how it can be used to orient innovation performance.

\section{Validity of the parameters used}

If merit there is, it is also related to the fact that most of the data used are easily accessible in the World Bank data sources. The exception is the data used for defining "Distance" which was equated to the "corruption perception index" (CPI) produced by Transparency International. This data source also is easily accessible. However, it does not include all the countries found in the World Bank data sets.

Consequently, it might be appropriate to have CPI expanded to same number of countries as the World Bank data set or to have the World Bank explore the development of a data set related to measuring trust or corruption.

Additionally, it is interesting to note that Escresa and Picci (2017) have recently published a new measure of corruption. This could potentially be used in future innovation evaluation using the $R_{i}$ metric.

It should be noted that the definition of "Distance" should not be limited to CPI or any other definition of corruption. There are other dimensions to "Distance" that could also be considered, such as different measures of trust (Naef \& Schupp, 2009; Salamon, 2003) or a measure of the confidence in something happening in the expected time limit. In this latter case, the World Bank's "Logistics performance index" could be an expression of that. This index “...reflects perceptions of a country's logistics performance based on the efficiency of the customs clearance process, quality of trade- and transport-related infrastructure, ease of arranging competitively priced international shipments, quality of logistics services, ability to track and trace consignments and frequency with which shipments reach the consignee within the scheduled time...". When plotting Distance based on the CPI against Distance based on this logistics performance index, a fairly strong trend appears between the two (Fig. 18). This suggests that potentially the "Distance" metric could be defined as an average of CPI (or equivalent) and logistics performance.

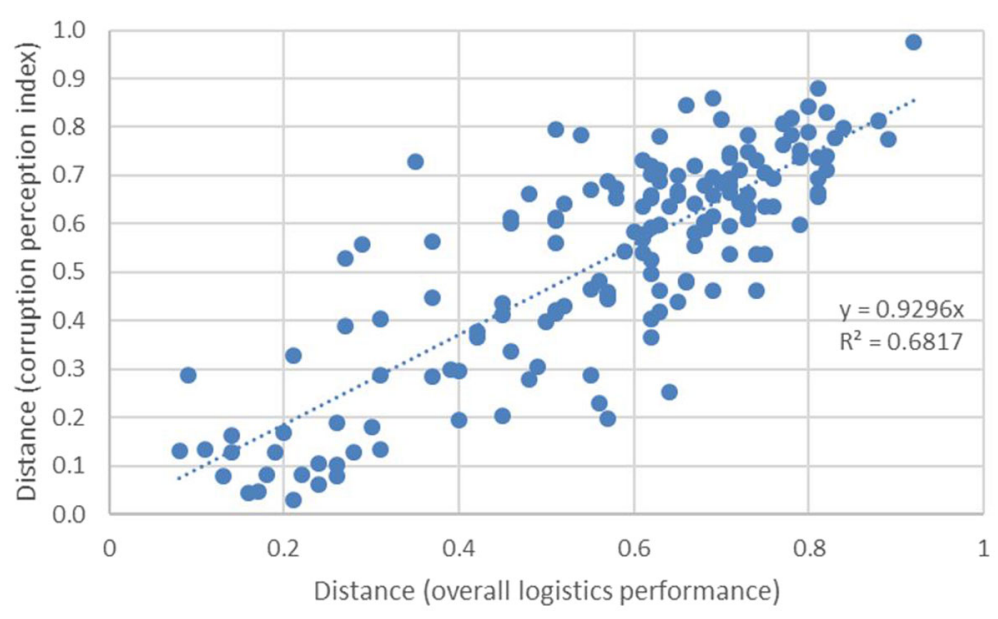

Fig. 18 Correlation between CPI and logistics definition of Distance 


\section{Possible other fluid mechanical analogies}

Beyond the Reynolds number analogy, two other pipe flow measures could potentially be used to help illustrate other dimensions of innovation for a particular organisation or country.

\section{Speed of change}

The speed of change $(V)$ is determined using an adopted form of the average speed of flow in a pipe and is defined by Eq. (4) (Appendix 1):

$$
V=\frac{P}{\Delta p \pi\left(\frac{D}{2}\right)^{2}}
$$

The variable definitions are the same as those for the innovation metric $R_{i}$ (see Eq. (1)).

The results are plotted against the $R_{i}$ number (see Fig. 19). Here again it is interesting to note that the countries found in the turbulent zone also have the fastest rate or speed of change.

\section{Resistance to change}

Resistance to change, $f_{r}$, is defined separately for the laminar case and for the turbulent case and is defined by an adapted form of the pipe flow friction. It is defined by Eqs. (3) and (4) where one additional variable is included (Colebrook, 1938-1939).

$$
\text { Laminar change case } f_{r}=\frac{64}{R_{i}}
$$

Turbulent change case $\frac{1}{\sqrt{f_{r}}}=-2 \ln \left[\frac{\varepsilon}{3.7}+\frac{2.51}{R_{e} \sqrt{f_{r}}}\right]$

where $\varepsilon$ is defined as the relative size of the organisation:

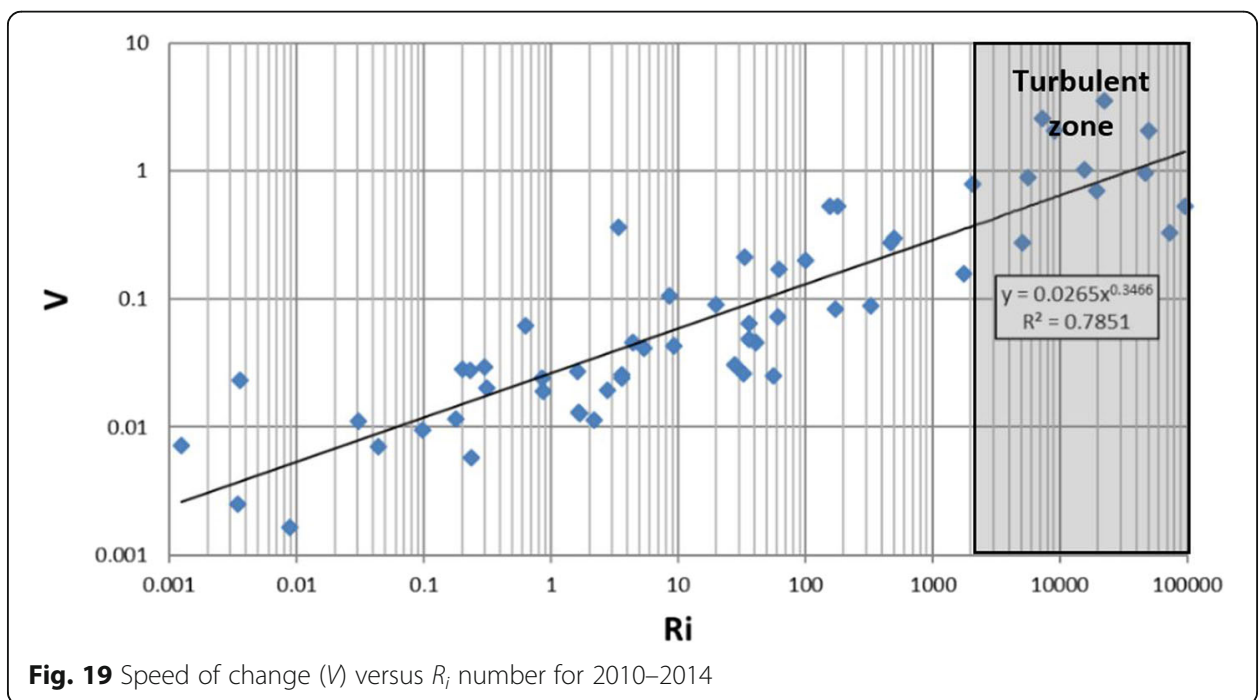




$$
\varepsilon=\frac{\text { population }}{\text { world population }}
$$

Plotting resistance to change, $f_{r}$, against $R_{i}$ indicates how this parameter changes as it crosses into the turbulent zone (Fig. 20). This result also indicates how, for countries with low $R_{i}$ numbers, the resistance to change is estimated to be quite high as compared with those countries that have a much higher $R_{i}$ number. One could state that, based on this model, countries with a high $R_{i}$ number can more easily and quickly adapt to changing environments.

\section{Conceptual model of an organisation}

In the laminar pipe flow case (Fig. 1) as described by Obeng (2012), there is no mixing of the green ink that he introduced into that flow. That is indeed one characteristic of laminar pipe flow. Another characteristic of laminar pipe flow could be determined if one were to measure the speed of the flow in a pipe at different distances from the pipe wall. One would then find a distinct parabolic velocity profile (see Fig. 21). The flow speed at the pipe wall would be essentially zero while flow speed in the middle of the pipe cross-section would be maximum. Furthermore, there would be very little mixing in the flow as illustrated by Obeng (2012) and Fig. 1a.

In the turbulent pipe flow case (Fig. 1b) as described by Obeng (2012), there is a lot of mixing of the injected green ink due to a growing number of eddies, vortices and flow instabilities. This is indeed one characteristic of turbulent pipe flow. Another characteristic of turbulent pipe flow could be determined if one were to measure the speed of the flow in the pipe at different distances from the pipe wall. In the turbulent flow case, one would see a net higher flow speed as compared to the laminar case. In addition, one would see a rather flat velocity profile. Still, the slowest flow speed would be near the pipe wall, while the maximum speed would be reached closer to the pipe wall and would remain the same across the pipe cross-section until the measurements gets close to the far side of the pipe (Fig.

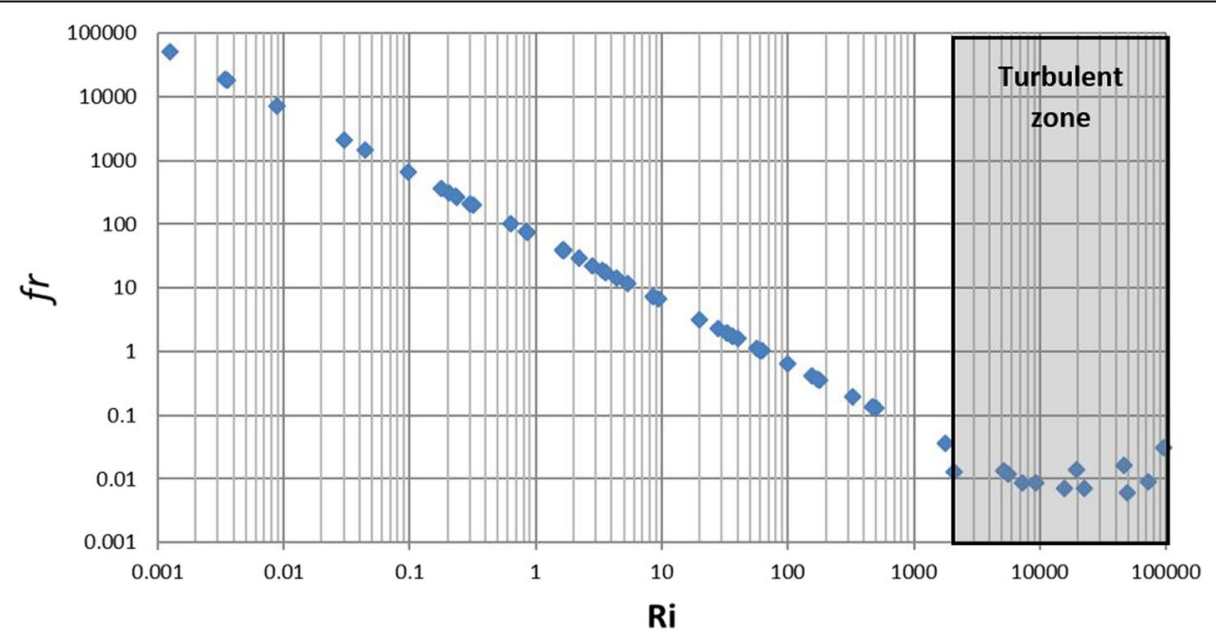

Fig. 20 Resistance to change versus the innovation metric $R_{i}$ for 2010-2014 


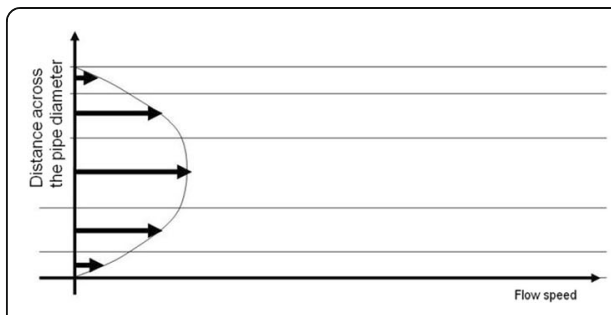

a) Laminar pipe flow speed profile

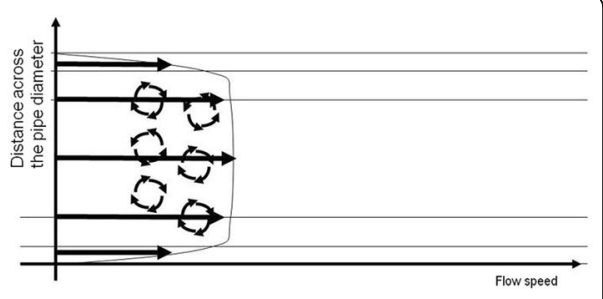

b) Turbulent pipe flow speed profile

Fig. 21 Flow in a straight pipe

21b). In this case, there would also be a lot of eddies and vortices in the flow mixing the flow substantially as illustrated by Obeng (2012) and Fig. 1b.

These laminar and turbulent flow characteristics can be used as an analogy of what happens in an organisation as it transitions between a laminar state of innovation to a turbulent state of innovation.

In the laminar state of innovation, as with pipe flow, there would be very little interaction between different parts of an organisation in terms of innovation or the development of concepts and ideas. Essentially, an organisation in a laminar state of innovation has the same characteristics as an organisation that is heavily "siloed". According to McDowell and Anderson (2019) "In heavily siloed organisations, leaders are the main pathway (and often bottleneck) to cross-functional collaboration". Therefore, leaders set the pace and as they are at the centre of the organisation, it holds that they would be in the centre and fastest part of the flow as described in this pipe flow analogy.

An interesting observation can be made from the works of Islam and Zein (2018), Garms and Engelen (2019) and Kraiczy, Hack, and Kellermanns (2015). These three papers explore the impact of having the innovation function embedded in the top management team leading high technology small- to medium-size companies. This observation suggests that highest performing organisations have the innovation function accompany them at the centre of the flow as illustrated in Fig. 22a.

As the organisation transitions to higher speed turbulent flow, potentially the $\mathrm{RnD}$ function could expand including more resources from across an organisation as suggested by Fig. 22b. This approach seems to be favoured by some companies such as Google (Steiber, 2014) where innovation guiding principles include themes like "people

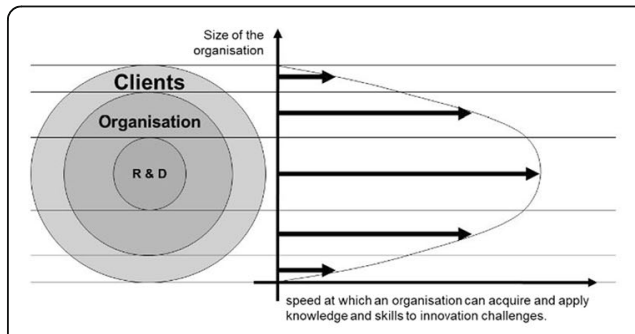

a) laminar flow RnD state

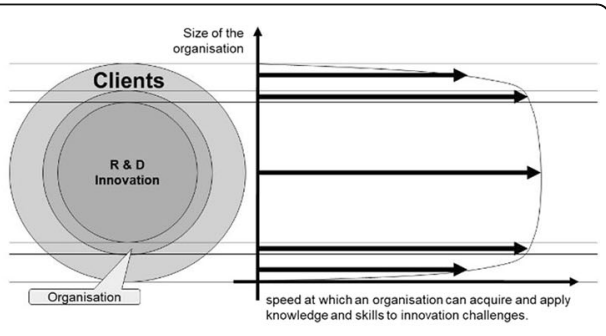

b) turbulent flow RnD state

Fig. 22 Possible laminar to turbulent transition impact on the RnD function 
centric approach" and "ambidextrous organisation" that encourages its employees to devote up to $20 \%$ of their time to side projects (Robinson, 2018).

This pipe flow speed profile analogy points to conceptually defining an organisation's innovation system in three dimensions starting with a two-dimensional view (see Fig. 23) of research and development, related to technology, economic or even social dimensions, at the organisation's central core. This central $\mathrm{RnD}$ function is embedded in any organisation whether it be governmental, industrial or entrepreneurial. In turn, the organisation is embedded in a society defined by clients of one kind or another and the general public. These three components are illustrated as circles of increasing size positioned concentrically as illustrated in Fig. 23.

The third dimension of this innovation system is speed as previously described by the velocity profile (see Fig 22).

\section{From nations to corporations and companies}

The quantitative assessment of the innovation metric, $R_{i}$, was made possible using an assumption that, from an "economic entity" point of view, nations are no different than organisations such as corporations and companies. Furthermore, based on the results from the quantitative assessment, it suggested that, in the case of innovation, the onset of the laminar to turbulent transition, is closer to $R_{i}=1$ while the fully turbulent threshold can be estimated to be at $R_{i}=1000$.

With this assumption and thresholds, it becomes possible to revisit the data available for corporations and companies and determine if the innovation metric can be used, in its current form, to estimate a corporation's innovation performance.

If the only data that is available is related to an organisation's effort in $\mathrm{RnD}$ (per cent of sales), the trend line relationship in Fig. 12b can be used to estimate the

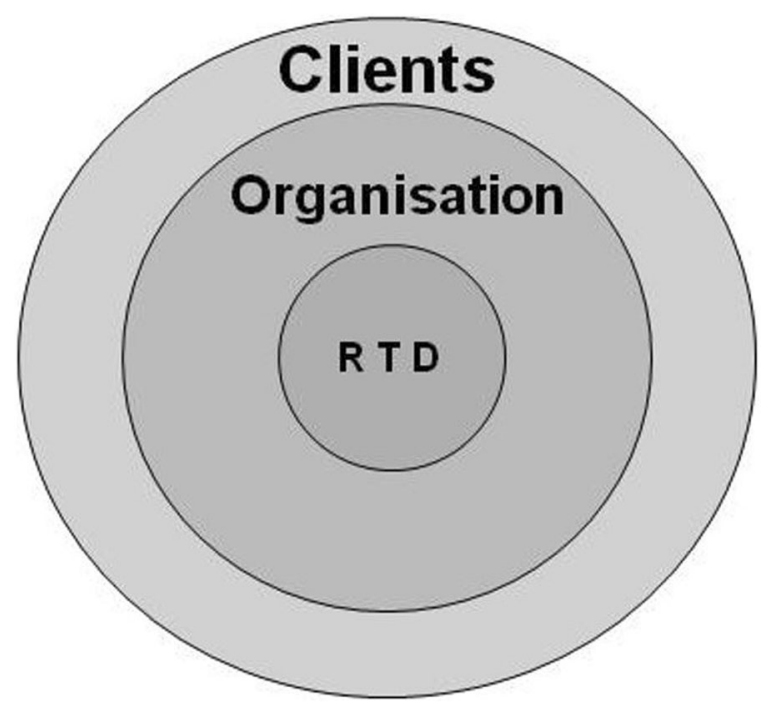

Fig. 23 A circular 2D model of society or nation 
organisations $R_{i}$ metric. To illustrate this point, $\mathrm{RnD}$ data (Power) for the companies listed in Appendix 2 (Lowe, 2013) is used to estimate the respective states of innovation. These $R_{i}$ estimates are plotted against Power in Fig. 24.

As compared to the organisations (nations) used in the quantitative assessment, one can see that this group of organisations overlap with the top end of the World Bank data set. Furthermore, a couple of these organisations actually are found just under the fully turbulent threshold of 1000 . This is a bit surprising considering that all the organisations found in Appendix 2 are considered amongst the most innovative in their respective industries.

If SG\&A data can also be gleaned from an organisation's annual report, it becomes possible to determine the ratio of Rnd expenses (Power) to total SG\&A expenses (Losses). It is important to note that, as described by Lowe (2013), RnD expenses are technically SG\&A expenses. Consequently, total SG\&A or rather Losses is the sum of the reported \%SG\&A and the reported \% RnD. The resulting ratio illustrates the importance of $\mathrm{RnD}$ in a corporation's overall total SG\&A envelop.

Plotting $R_{i}$ against this ratio for the World Bank data set, it is possible to establish a trend line relationship as illustrated in Fig. 25. Using that trend line relationship along with the Lowe (2013) data set (see Appendix 2), it is possible to overlay onto Fig, 25 the state of innovation estimates for this data set.

The use of the Power/Losses ratio pushed the state of innovation estimate for Lowe's organisations a bit higher to the point where all these organisations are now over the "fully" turbulent innovation threshold of 1000 . This is a better reflection of innovation reputation of these organisations.

If it can be assumed that viscosity (resistance to communications) and distance (the inverse of trust) for these organisations can be approximated by the viscosity and distance of the host country, then it is possible to further improve the state of innovation measure as suggested by Fig. 26 .

Refinement of viscosity and distance requires a case by case evaluation of viscosity (resistance to communication) and distance (inverse of trust). Such a refinement would

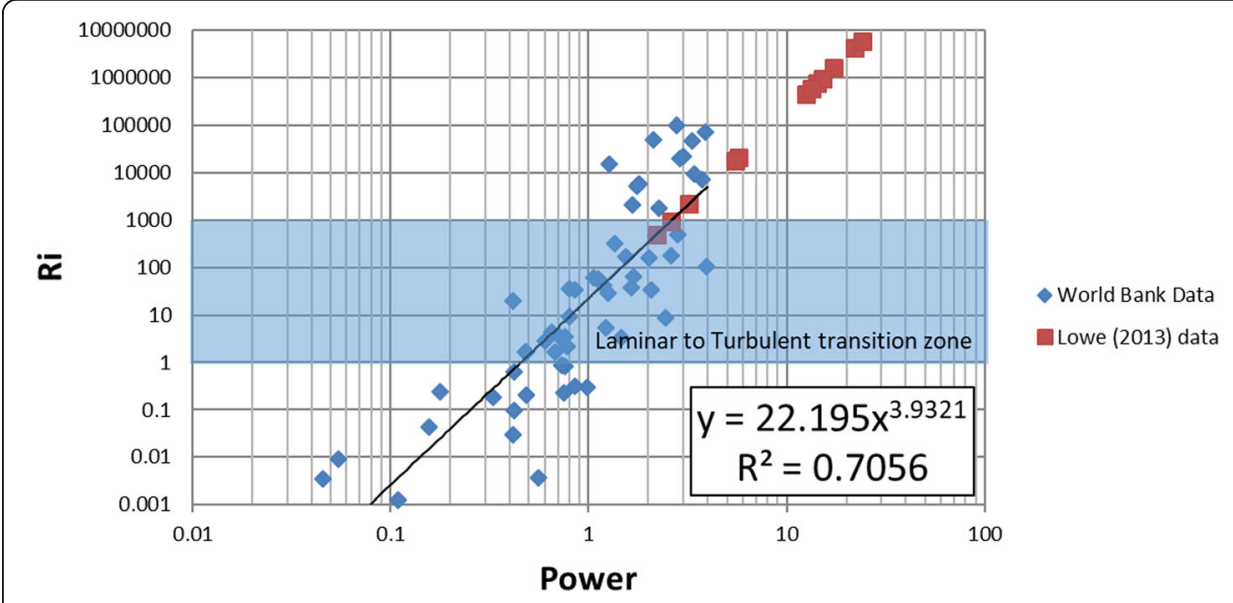

Fig. 24 Estimating the state of innovation using only an organisation's RnD expenses (Power) 


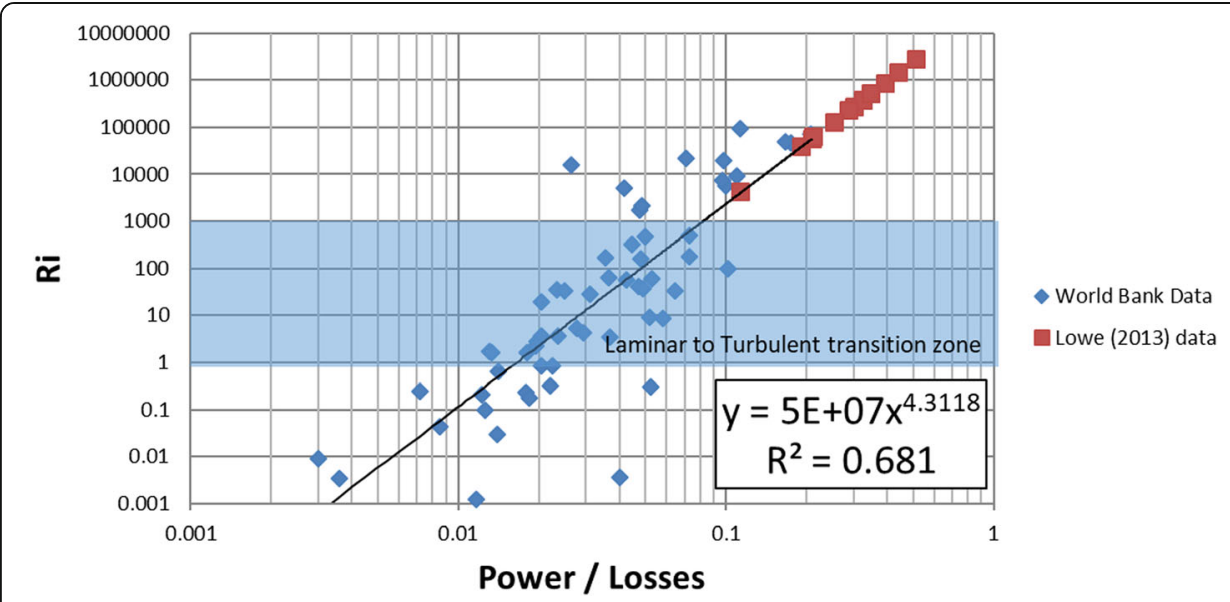

Fig. 25 Estimating the state of innovation using the ratio of Power over Losses

be accomplished by an appropriately designed survey of both employees and customers.

Finally, with respect to completing the state of innovation evaluation using $R_{i}$, of any organisation, it would require getting an organisation's data related Density of ideas and Length of experience as described in the definition of the metric (Eq. 1).

\section{Relationship with the literature}

It should be underlined that the present development is not the first application of the Reynolds number outside of the fluid mechanics field. The work of Los (2003) explores market risk and examines the use of a financial Reynolds number where a "typical high financial Reynolds number empirically measures the onset of

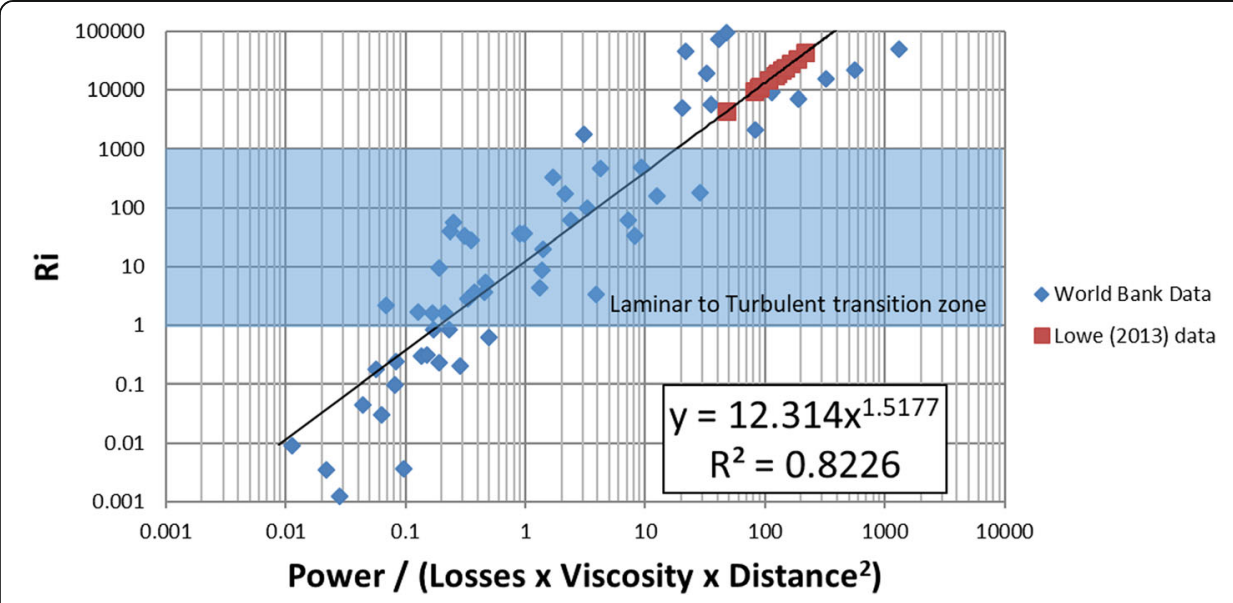

Fig. 26 Improving the state of innovation estimate using the ratio of Power over Losses, Viscosity and Distance squared 
intermittency and financial turbulence". While Kamenshchikov (2014) extends the Reynolds number concept to examine complex systems by using it as a basic phase parameter as one possible control metric.

Beyond these two references, the use of the Reynolds number outside of the fluid mechanics field fits into a larger research context related to innovation. As mentioned earlier, the meaning of the term innovation has evolved from the notion of heresy in the seventeenth century (Green, 2013) to a desired current state of increasing competitiveness. In this current state, the work of Freeman and Soete (1997) The Economics of Industrial Innovation is seen as a classic by some having a focus on science and technology policy. The work of Stan Metcalfe (1994) "Evolutionary economics and technology policy" tends to complement this economic point of view. With the turn of the century, the point of view of economics has evolved to one of management as described in the work of Antonelli (2009) "The economics of innovation: from the classical legacies to the economics of complexity". Now, as Professor Stuart MacDonald stated in a communication (2018) with the author "...industry rather than government policy or social forces is the driving force behind innovation and the focus is on practical steps to manage innovation and - above all else - to measure it."

Lord Kelvin is credited with stating: "If you can not measure it, you can not improve it". It is indeed this desire to improve the innovation process that drives the need to quantify innovation, measure it and ultimately find practical means to improve it especially in the context of a risk-averse industry where innovation, as perceived, is likened to "be first to be second" or "...the second mouse gets the cheese".

\section{Conclusion}

The challenge to improving innovation in an organisation is limited by the metrics used to measure it. In the present case, dimensions related to where an organisation is on an innovation spectrum, to the speed with which an organisation is innovating and to the resistance holding it back from innovating are considered key elements than could be used to adequately measure innovation and orient its improvement.

Developing insights on these three dimensions was accomplished by first proposing a hypothesis that suggested that the state of an organisation's innovation performance can be illustrated using a pipe flow analogy and quantified using an adapted form of the Reynolds number. Subsequent testing of the hypothesis through qualitative and quantitative assessments of the innovation metric, $R_{i}$, proved, to the limits of the data used, that the hypothesis is valid. This justified an initial demonstration of the $R_{i}$ metric to both track changes in an organisation's innovation performance and help to orient possible avenues for improvement. Along with insights drawn from the discussions of some of the limits and issues related with the $R_{i}$ metric the following conclusions can be drawn:

(i) The $R_{i}$ metric, an adapted form of the Reynolds number, can be used to quantify the state of innovation of an organisation where that organisation is a 
country. Furthermore, the $R_{i}$ metric can be used to track annual changes in the state of innovation of an organisation such as a country.

(ii) The $R_{i}$ values of 2000 and 4000 for the transition from laminar to turbulent needs to be investigated further. Based on the comparison with the GCI metric, the thresholds could potentially be as low as $R_{i}=1$ for the onset of turbulent flow and closer to $R_{i}=1000$ for fully developed turbulent flow.

(iii) The variables composing the $R_{i}$ metric behave as suggested by the literature. However, more research would be required to understand the dynamic between the $R_{i}$ metric and Losses (government expenditures) and the possible use of alternate or complementary data to define Distance (the inverse of trust).

(iv) Other pipe flow fluid mechanics analogies provide some insight to the speed ( $V$ ) with which an organisation is innovating and to the resistance $\left(f_{r}\right)$ holding it back innovation.

(v) The development, proof of this pipe flow analogy and subsequent discussion suggests that $\mathrm{RnD}$ is found at the central core of an organisation. Conceptually, as an organisation passes from a laminar state of innovation performance to a turbulent state, the size of this RnD core increases in size, by engaging more members of the organisation in innovation.

(vi) In its current form, the $R_{i}$ metric can be used now, with publicly available data to approximate the state of innovation of organisations such as corporations and companies.

Independent of these conclusions, the greatest value of this development is related to its contribution to the global conversation on innovation.

\section{Methods}

The aim of the paper was to explore the development of an innovation metric based on a pipe flow analogy. This was accomplished by defining a hypothesis that the state of innovation can be measured by an adapted form of the Reynolds number. Once defined, the hypothesis was tested using both qualitative and quantitative assessments.

The quantitative assessment was made possible by populating the innovation metric, comparing the results with established innovation and competitiveness indices and then confirming the qualitative assessment. Populating the metric was accomplished with data primarily from the World Bank. Data was downloaded from the World Bank and input into a spreadsheet program. As noted, at the time of data preparation for this paper, it was noticed that a number of data points were missing for some years. In order to compensate for this missing data, it was decided to use an average of the values for the years 2010 to 2014. For any particular year in that range where there was a blank in the data, the average was determined over the "non-blank" years.

Confirming the qualitative assessment was accomplished by completing a sensitivity analysis. Statistical analysis was limited to best fit trend line relationships, where $R^{2}$ provided a measure of fit. After testing the innovation metric, an illustrative case was established using examples drawn from the quantitative assessment.

Subsequent discussion focused on addressing issues and limitations. 


\section{Legend}

\begin{tabular}{lll}
\hline Symbol & Fluid mechanics meaning & Innovation metric meaning \\
\hline$\varepsilon$ & Roughness pipe wall & Relative size of an organisation \\
$\mu$ & Fluid viscosity & $\begin{array}{l}\text { Restrictions to communication, interactions, } \\
\text { interdependence } \\
\text { Density of ideas per person }\end{array}$ \\
$\rho$ & Fluid density & \\
$A$ & Pipe cross-section area & Distance between people (inverse of trust) \\
$D$ & Pipe diameter & Length of experience \\
$L$ & Pipe length & Importance of RnD financial input \\
$P$ & Power required to maintain volumetric flow rate for & \\
& associated pressure loss & \\
$R_{e}$ & Reynolds number & Innovation metric \\
$R_{i}$ & n/a & Innovation speed \\
$V$ & Flow velocity & Resistance to change \\
$f_{r}$ & Friction & Losses as defined by the total cost of \\
$\Delta p$ & Pressure loss over length of pipe & government or total SG\&A \\
\hline
\end{tabular}

\section{Appendix 1}

\section{Reynolds number}

First introduced by George Stokes (circ. 1851) and popularised by Osborne Reynolds (circ. 1883), the Reynolds number is an adimensional quantity used to predict similar flow characteristics in different flow regimes such as scaling pipe flow behaviour from a lab experiment to full-scale application. It is defined as the product of density $(\rho)$, speed $(V)$ and length $(L)$ divided by the fluid viscosity $(\mu)$ :

$$
R_{e}=\frac{\rho V L}{\mu}
$$

The average flow speed, $V$, can be defined as a function of volumetric flow rate $(Q)$ and pipe diameter $(D)$ :

$$
V=\frac{Q}{\pi\left(\frac{D}{2}\right)^{2}}
$$

And volumetric flow rate, $Q$, can be defined as a function power $(P)$ and pressure drop $(\Delta p)$ :

$$
Q=\frac{P}{\Delta p}
$$

Substituting Eq. (10) into Eq. (9) followed by substituting Eq. (9) into Eq. (8) produces an expanded form of the Reynolds number:

$$
R_{e}=\frac{4 \rho P L}{\mu \Delta p \pi D^{2}}
$$

It is this expanded form of the Reynolds number that is referred to in the innovation metric development. 


\section{Appendix 2}

Table 1 Lowe (2013) data set

\begin{tabular}{|l|c|c|c|c|}
\hline \multirow{2}{*}{ Corporation } & Power & & Losses & Power / Losses \\
\cline { 2 - 6 } & $\%$ RnD & $\%$ SG\&A & Total \% SG\&A & $\%$ \\
\hline Merck & 17.3 & 27 & 44.3 & 39.1 \\
\hline Pfizer & 14.2 & 33 & 47.2 & 30.1 \\
\hline Astra Zeneca & 15.1 & 31.4 & 46.5 & 32.5 \\
\hline BMS & 22 & 28 & 50 & 44.0 \\
\hline Biogen & 24 & 23 & 47 & 51.1 \\
\hline Johnson \& Johnson & 12.5 & 31 & 43.5 & 28.7 \\
\hline Hewlett-Packard & 2.6 & 11 & 13.6 & 19.1 \\
\hline IBM & 5.7 & 21.5 & 27.2 & 21.0 \\
\hline Microsoft & 13.3 & 25 & 38.3 & 34.7 \\
\hline 3M & 5.5 & 20.4 & 25.9 & 21.2 \\
\hline Apple & 2.2 & 6.5 & 8.7 & 25.3 \\
\hline GE & 3.2 & 25 & 28.2 & 11.3 \\
\hline
\end{tabular}

\section{Abbreviations}

CPI: Corruption Perceptions Index; BII: Bloomberg Innovation Index; GCl: Global Competitiveness Index; GDP: Gross domestic product; Gll: Global Innovation Index; IMD: International Institute for Management Development; $R^{2}$ : Coefficient of determination; RnD: Research and development; TED: Technology, entertainment, design; SG\&A: Selling, general and administrative expenses

\section{Acknowledgements}

The fluid mechanic innovation metric concept was in development since the late 1980s. It started with a conversation between the author and a mechanical engineering professor from India on a sabbatical stay at Université Laval in Quebec City. The conversation explored the conceptual analogy drawn between the highly specialised Western societies and the intellectually freer flowing Indian society and laminar and turbulent pipe flow mechanics. Since that time, the concept evolved over time and academic environments (Université du Québec en Abitibi-Témiscamingue and McGill University) before meeting the reality of an industrial environment. The industrial reality required a means to describe the importance of $\mathrm{RnD}$ and innovation, which motivated completing the resulting model and associated evaluation. Consequently, the author would like to acknowledge the Indian professor and that conservation with a young graduate student.

Special thanks are expressed to Christopher Green, Professor of Economics, McGill University for the initial critique of this work; to Professor Stuart MacDonald, School of Business, University of Leicester for advice and critique especially as it relates to the economics literature; and to the two anonymous referees who raised pointed questions and critiques in the review process.

Finally, the author would like to thank Metso for allowing to both prepare and publish this paper as well as two colleagues Lars Gronvall, VP RnD, Mining Equipment, for asking if an innovation metric could be developed and Lauren Markofsky, Marketing Manager, Global Services, for reviewing the final paper version for clarity and critique.

\section{Authors' contributions}

PR is the sole contributor to the development of this metric and its implementation in this paper. The author read and approved the final manuscript

\section{Authors' information}

Peter Radziszewski ('83, BASc Mech Eng, UBC; '86, MSc génie méc., ULaval; '92, PhD génie méc., ULaval) has completed research work in mineral processing (comminution) since his Masters on modelling of mill charge motion. This work has led him to the Abitibi (UQAT, 1991-2000), Australia (JKMRC, 1997-1998), Montreal (McGill, Mechanical Engineering, since 2001) and the Canadian Space Agency (2007-2008). His research efforts have contributed to the development of discrete element methods in modelling of tumbling mill charge dynamics, to the development of a steel media wear prediction methodology and to bringing real-time charge motion simulation and prediction closer to the mill operators with the collaboration of COREM. While his teaching activities in engineering design have led to the development of an electric snowmobile, a hybrid race car, contributions to powertrain modelling and simulation as well as the development of a prototype wheel for lunar mobility inspired by tumbling mill charge motion. He also has worked with the cement industry, with automation and control related to the pulp and paper industry, thermodynamic processes and heat transfer and laser scanning in particle board roughness measurements. He is the author/co-author of over 100 paper and conference proceedings.

Since joining Metso in 2012, Dr. Peter Radziszewski has contributed to the continuous development of an innovation culture, as well as, to the exploration of innovative equipment and process concepts covering comminution, flotation, sensor development and tailing processing. Currently, he is a consultant to the mineral processing industry working out of Vancouver, BC, Canada. 
Funding

No external funding was obtained to support the development and publication of this paper.

\section{Availability of data and materials}

Most of the data can be found in the World Bank data repository (http://data.worldbank.org/).

Data related to corruption is found in the reports of Transparency International (http://www.transparency.org/cpi2014/)

Innovation index data sets were found in the following two sites: the Bloomberg Innovation Index (https://www.

bloomberg.com/graphics/2015-innovative-countries/) and the Global Innovation Index (https://www.

globalinnovationindex.org/userfiles/file/reportpdf/Gll-2014-v5.pdf).

Competitiveness data sets were found in the following three sites: the IMD World Competitiveness Index (https:// worldcompetitiveness.imd.org/), the Global Competitiveness Report Library (http://reports.weforum.org/globalcompetitiveness-report-2015-2016/competitiveness-library/) and the EU Regional Competitiveness Index 2013 (https:// ec.europa.eu/regional_policy/sources/docgener/studies/pdf/6th_report/rci_2013_report_final.pdf).

\section{Competing interests}

The author worked for Metso which is a mineral process equipment manufacturer and service provider. RnD and innovation is an on-going concern in Metso's development and for its customers.

Received: 19 June 2019 Accepted: 6 March 2020

\section{Published online: 28 May 2020}

\section{References}

Annoni, P., \& Dijkstra, L. (2013). EU Regional Competitiveness Index (p. 183). European Commission, Joint Research Centre. Antonelli, C. (2009). The economics of innovation: from the classical legacies to the economics of complexity. Economics of Innovation and New Technology, 18(7), 611-646.

Backman E., \& Ellmarker J. (2017). (A Literature Review of Innovation Science) (http://hh.diva-portal.org/smash/get/diva2:1 075117/FULLTEXT01.pdf. Accessed 17 June 2019).

BII (2015), The Bloomberg Innovation Index (https:/www.bloomberg.com/graphics/2015-innovative-countries/, accessed June 17 2019)

Boh, W. F., Evaristo, R., \& Ouderkirk, A. (2014). Balancing breadth and depth of expertise for innovation: a 3M story. Research Policy, 43, 349-366.

Clark, J., \& Guy, K. (1998). Innovation and competitiveness: a review. Technology Analysis and Strategic Management, 10(3), 363-395.

Colebrook, C. F. (1938-1939). Turbulent flow in pipes, with particular reference to the transition region between the smooth and rough pipe laws. Journal of the Institution of Civil Engineers, 11, 133-156.

CPI (2014), Corruption Perception Index, Transparency International (http://www.transparency.org/cpi2014/results accessed 10 Apr 2018).

Escresa, L., \& Picci, L. (2017). A new cross-national measure of corruption. The World Bank Economic Review, 31(1), 196-219.

Freeman, C., \& Soete, L. (1997). The Economics of Industrial Innovation. London: Routledge.

Galvez, D., Camargo, M., Rodriguez, J., \& Morel, L. (2013). PII - Potential Innovation Index: a tool to benchmark innovation capabilities in international context. Journal of Technology Management \& Innovation, 8(4), 36-45.

Garms, F. P., \& Engelen, A. (2019). Innovation and R\&D in the upper echelons - the associated between the CTO's power depth and breadth and the TMT's commitment to innovation, J. Product Innovation Management, 36(1), 87-106.

GCI (2018), Global Competitiveness Report Library (http://reports.weforum.org/global-competitiveness-report-2015-2016/ competitiveness-library/ accessed 10 Apr 2018).

GII (2014), The Global Innovation Index - the human factor in innovation (https:/www.globalinnovationindex.org/userfiles/ file/reportpdf/Gll-2014-v5.pdf, accessed June 17, 2019).

Green, E. (2013), Innovation - the history of a buzzword, The Atlantic (https:/www.theatlantic.com/business/archive/2013/06/ innovation-the-history-of-a-buzzword/277067/, accessed 14 Nov 2018)

Hamby, D. M. (1994). A review of techniques for parameter sensitivity analysis of environmental models. Environmental monitoring and assessment, 32, 135-154.

Herstad, S. J., Sandven, T., \& Ebersberger, B. (2015). Recruitment, knowledge integration and modes of innovation. Research Policy, 44, 138-153.

Ibert, O., \& Muller, F. C. (2015). Network dynamics in constellations of cultural differences: relational distance in innovation processes in legal services and biotechnology. Research Policy, 44, 181-194.

IMD (2018), IMD World Competitiveness Index (https://worldcompetitiveness.imd.org/ accessed 10 Apr 2018).

Islam, E., \& Zein, J. (2018). (Inventor CEOs, J. Financial Economics, Forthcoming; 31st Australasian Finance and Banking Conference). Available at SSRN: https://ssrn.com/abstract=3152200 or http://dx.doi.org/10.2139/ssrn.3152200.

Kamenshchikov, S. (2014). Extend pripopine theorem: method for universal characterization of complex system evolution. Chaos and Complexity Letters, 8(1), 63-71.

Kotter, J. (2011), Can you handle an exponential rate of change?, Forbes (https://www.forbes.com/sites/johnkotter/2011/07/1 9/can-you-handle-an-exponential-rate-of-change/\#8cf84404eb05, accessed 14 Nov 2018)

Kraiczy, N. D., Hack, A., \& Kellermanns, F. W. (2015). The relationship between top management team innovation orientation and firm growth - the mediating role of firm innovativeness. International Journal of Innovation Management, 19(1), 24.

Lowe, D. (2013), But don't drug companies spend more on marketing?, In the Pipe Line, Science Translational Medicine, (https://blogs.sciencemag.org/pipeline/archives/2013/05/20/but_dont_drug_companies_spend_more_on_marketing, accessed 13 Oct 2019)

McDowell, T., Anderson, S. (2019), Making the invisible visible: how network analysis can lead to more successful organisational redesigns, Deloitte Insights (https://www2.deloitte.com/content/dam/insights/us/articles/4738_Flexibleorganizations/Dl_Flexible-organizations.pdf, accessed 19 Oct 2019) 
Melero, E., \& Palomeras, N. (2015). The Renaissance Man is not dead! The role of generalist in teams of inventors. Research Policy, 44, 154-167.

Metcalfe, S. (1994). Evolutionary economics and technology policy. Economic Journal, 104(425), 931-944.

Meyers, J. (2016), How do the world's biggest companies compare to the biggest economies, World Economic Forum (https://www.weforum.org/agenda/2016/10/corporations-not-countries-dominate-the-list-of-the-world-s-biggesteconomic-entities/, accessed 22 Aug 2019)

Mitchell, D.J. (2005), The impact of government spending on economic growth, Backgrounder, The Heritage Foundation, no. 1831 (www.heritage.org/research/budget/bg1831.cfm).

Morris, S. D., \& Klesner, J. L. (2010). Corruption and trust: theoretical considerations and evidence from Mexico. Comparative Political Studies, 43(10), 1258-1285.

Naef, M., \& Schupp, J. (2009). Measuring trust: experiments and surveys in contrast and combination.

Obeng, E. (2012), Smart failure for a fast-changing world, TEDGlobal (https://www.ted.com/talks/eddie_obeng_smart_failure_ for_a_fast_changing_world?language=en, accessed 14 Nov 2018)

Robinson, A. (2018), Want to boost your bottom line? Encourage your employees to work on side projects, Inc. (https://www inc.com/adam-robinson/google-employees-dedicate-20-percent-of-their-time-to-side-projects-heres-how-it-works.html, August 26, 2019)

Salamon, S. (2003). Trust that binds: the influence of collective felt trust on responsibility norms and organizational outcomes, PhD thesis. UBC Sunder School of Business.

Sheehan, J., \& Wyckoff, A. (2003). Targeting RnD: economic and policy implications of increasing RnD spending (p. JT00147720). Directorate for science, technology and industry, OECD, DSTI/DOC (2003)8.

Smith, J., Cruickshank, D. (2017), Curruption and the erosion of trust, World Economic Forum (https://www.weforum.org/ agenda/2017/01/corruption-and-the-erosion-of-trust/, accessed 22 Aug 2019)

Steiber, A. (2014). (The Google Model - Managing Continuous Innovation in a Rapidly Changing World), Switzerland: Springer Int'l Publishing.

Vega Gonzalez, L. R. (2005). Innovation rate of change measurement part 1: Information Technology. Journal of Applied Research and Technology, 3(3), 197-210.

Watson-Wyatt (2009), Communication ROI Study Report - capitalizing on effective communication, Watson Wyatt Worldwide (https://www.towerswatson.com/en-US/Insights/IC-Types/Survey-Research-Results/2009/12/20092010-CommunicationROI-Study-Report-Capitalizing-on-Effective-Communication)

\section{Publisher's Note}

Springer Nature remains neutral with regard to jurisdictional claims in published maps and institutional affiliations.

\section{Submit your manuscript to a SpringerOpen ${ }^{\circ}$ journal and benefit from:}

- Convenient online submission

- Rigorous peer review

- Open access: articles freely available online

- High visibility within the field

Retaining the copyright to your article

Submit your next manuscript at $\boldsymbol{\sim}$ springeropen.com 